\title{
Die räumlichen Vorstellungen der Byzantiner von der Ökumene* (4. bis 12. Jahrhundert)
}

Gliederung: 1. Vorbemerkungen - 2. Jedermanns persönliche Ökumene - 3. Politischkaiserliche Ökumene: Rom - 4. Frühchristliche Ökumene - 5. Eschatologische Ökumene - 6. Politisch-kaiserliche Ökumene: Byzanz vor den Kreuzzügen - 7. Anhang: Sprachliche Ökumene

\section{VORBEMERKUNGEN}

„Herrsche mit Gott, der Dich, mächtigster Herr, behütet, als Kaiser über die Ökumene!“ ruft der Literat, Philosoph und Polyhistor Michael Psellos dem Kaiser Konstantin IX. Monomachos (reg. 1042-1055) zu¹. In dem einen kurzen Satz finden sich (fast) alle Grundbegriffe, die oft und gerne mit Byzanz verbunden werden: Kaisertum, Christentum, Ökumene ${ }^{2}$. Eigentlich könnte man also summarisch Michael Psellos zitieren, um byzantinisches Raumverständnis und Ökumeneverständnis in einem Satz einzufangen. Doch dies wäre zu einfach: Die Begriffe „Ökumene“ bzw. „ökumenisch“ sind in ihrer Entwicklung seit der Zeitenwende zu vielfältig in ihren verschiedenen konkreten Anwendungen und in ihren Bedeutungsnuancierungen, die zum Teil auch im Hintergrund bzw. im Bereich des Unterbewußten verblieben, als daß sie durch einen Satz auszudrücken wären. „Ökumene“ ist, ähnlich dem EuropaBegriff $^{3}$, kaum losgelöst von ideologischen Grundvorstellungen denkbar, un-

* Das Konzept der vorliegenden Untersuchung schrieb ich im Frühjahr 2001 während eines mehrwöchigen Aufenthalts als Visiting Scholar in Dumbarton Oaks. Für diese hervorragende Arbeitsmöglichkeit danke ich dem Stiftungsrat und insbesondere der Direktorin für Byzantinische Studien, Alice-Mary Talbot, und dem Direktor von Dumbarton Oaks, Edward L. Keenan, auch an dieser Stelle aufrichtig. - Eine knappere Fassung der Studie erscheint in griechischer Sprache in den Akten des Symposions „Byzantium as Oecumene“, das in Athen von 29. 11. bis 2. 12. 2001 stattfand.

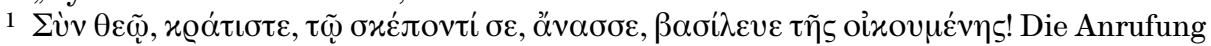
findet sich am Ende des von Michael Psellos verfaßten Trauergedichtes auf die um 1045 verstorbene Maria Skleraina (ed. M. D. SpadARo. Catania 1984, 448). - Nur wenige Jahre früher datieren zwei bildliche Darstellungen der kaiserlichen „Dreifaltigkeit“, die aus Konstantinos Monomachos, Zoe und deren Schwester Theodora besteht, auf den Emails der Budapester „Monomachos-Krone“ und in einer Miniatur des Chryso-

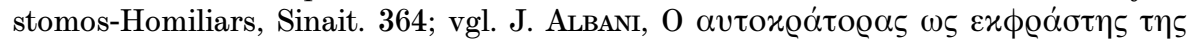

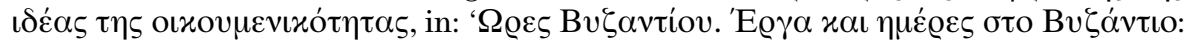

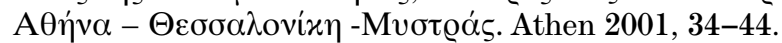

2 Eine klassische Präsentation des Sachverhaltes bei H. Hunger, Reich der Neuen Mitte. Der christliche Geist der byzantinischen Kultur. Graz-Wien-Köln 1965, vgl. den überarbeiteten Neudruck wesentlicher Abschnitte unter dem Titel „Konstantinopel und Kaisertum als <Neue Mitte> des Oströmischen Reiches“ in: M. Restle (Hrsg.), Epidosis. München 1989, Nr. XX.

3 Zu diesem vgl. jetzt Kl. Oschema, Der Europa-Begriff im Hoch- und Spätmittelalter, zwischen geographischem Weltbild und kultureller Konnotation. Jahrb. f. Europ. Gesch. 2 (2001) 191-235. - Zum byzantinischen Europa-Begriff: J. KoDER, 'O ő@o

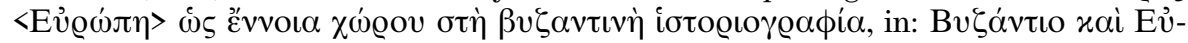


ter denen in unserer Zeit kirchenpolitische Konnotationen wohl vorherrschen.

Versucht man diese semantische Loslösung im Zusammenhang mit einer konkreten menschlichen Organisationsform dennoch, um die geographische Bedeutung des griechischen Wortes oikumene auszuloten, so denkt man in erster Linie an dessen siedlungsgeschichtliche Bedeutungskomponente, also den <von Menschen> besiedelten Raum, die <von Menschen> bewohnte Landschaft und die Beziehung zu dieser. Die Besiedlung einer solchen Ökumene erfolgt durch eine Gruppe, die durch Identifikationsmerkmale als zusammengehörig erkennbar ist; je nach dem sozialen Umfeld und dessen gruppenspezifischen politischen und kulturellen Bezugsaspekten wird der geographische Raum der Ökumene unterschiedlich dimensioniert.

Nun ist es nicht möglich, das kollektive Raumverständnis irgendeiner Gruppe, zu welcher Zeit auch immer, gleichgültig ob in Geschichte oder Gegenwart, insgesamt zu beschreiben, da die menschliche Befähigung zum Verstehen des Raumes in ihrer Komplexität die Möglichkeiten der rein sprachlichen (nicht-bildlichen) Ausdrucksfähigkeit übersteigt, so daß - unabhängig von der ausreichenden Verfügbarkeit und der Qualität bildlicher oder sprachlicher Zeugnisse - nur Annäherungen möglich sind, worauf Arnold Smith nachdrücklich hinweist: „Despite the richness of language and vocabulary, the relationship of linguistic expression to the richness of the world itself is sparse and partial"4.

Wir können hier also auch für die Byzantiner als Bewohner zentraler Großräume des östlichen Euromediterraneums nur versuchen, ihr Denken und Fühlen in bezug auf ihre Lebenswelt nachzuempfinden, und dies vor allem, soweit sie denjenigen Gesellschaftsschichten angehören, die wir in den Quellen - vermeintlich - repräsentiert finden. In den folgenden Überlegungen sollen vorzugsweise die ideologischen und politischen Komponenten der Bedeutung von oikumene in byzantinischen schriftlichen Quellen in Betracht gezogen werden, sowie als Anhang, somit nur ansatzweise, die Sprache als wesentlicher Faktor eines literarischen und wissenschaftlichen Ökumenebegriffs.

\section{JEDERMANNS PERSÖNLICHE ÖKUMENE}

Die persönliche bzw. die subjektive Ökumene des Individuums ist geographisch mit den in den folgenden Abschnitten zu behandelnden byzantinischen „Ökumenen“ nicht oder nur mittelbar in Übereinstimmung zu bringen, da diese - unabhängig von jeder ideologischen, kulturellen oder politischen Komponente - zu großräumig konzipiert sind, als daß sie eine persönlich bestimmte, räumlich begrenzte, „subjektive“ Orientierung (ein „Heimatgefühl“)

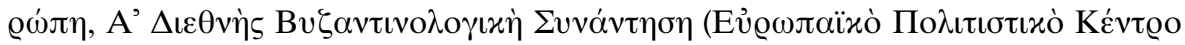
$\Delta \varepsilon \lambda \phi \tilde{\omega} v)$. Athen 1987, 63-74.

4 A. Sмттн, Spatial Cognition Without Spatial Concepts, in: Spatial Cognition. Foundations and Applications. Annual Conference of the Cognitive Science Society of Ireland, 1998. Amsterdam / Philadelphia 2000, 127-136, hier 135. - Vorweg möchte ich ausdrücklich auf die Selbstbeschränkung hinweisen, daß ich mich lediglich textlicher Quellen bediene, nicht bildlicher. Allgemein zur Bild-Wort-Beziehung in Byzanz s. G. Lange, Bild und Wort. Die katechetischen Funktionen des Bildes in der griechischen Theologie des sechsten bis neunten Jahrhunderts. 2. Auflage. Paderborn 1999, 8-12, 268-279. Speziell zu unserer Fragestellung die einschlägigen Beiträge in dem in A. 1

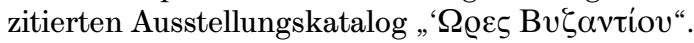


bieten könnten. Die „subjektive“ Ökumene korreliert mit dem Begriff „Heimat", wobei der erste hier in Betracht zu ziehende Begriff abstrahierend von einer siedlungsgeographischen Grundvorstellung ausgeht, während „Heimat" ${ }^{\text {"5 }}$ die Summe persönlicher Erfahrung zum Ausdruck bringt.

Der geographische Raum, auf den sich jeder unreflektiert und von den genannten Komponenten unabhängig beziehen kann, ist der im Alltag mit ihm vertrauten anderen Individuen (positiv oder negativ) unmittelbar erlebte und erlebbare Raum, der „Lebensraum“, die persönliche Ökumene ${ }^{6}$. Er umfaßt jedenfalls das Gebiet innerhalb einer alltäglich oder regelmäßig (z. B. allwöchentlich) erreichbaren Distanz, soweit dies eben die persönliche Mobilität ermöglicht, also der Distanz zu Fuß oder auf einem (langsamen) Reittier bzw. sonst einem Fortbewegungsmittel, das uns zu vertrauten Menschen, Tieren und Dingen bringt: Er betrifft den Besuch von Verwandten und Freunden, den Kirchgang an Sonntagen und Festtagen, den Geschäftsgang zum Markt (Wochenmarkt, Messe). Siedlungsgeographisch konkretisiert besteht diese persönliche Ökumene aus einem zentralen Ort, der in die jeweils „begehbare“, zu Fuß erreichbare Umgebung eingebettet ist: einem Dorf, einer kleinen Stadt, einem Kloster, einer Festung, oder auch dem Zentralort eines Bezirkes bzw. dem Pfarrsprengel einer größeren Stadt (Nicht nur Großstädte, wie Konstantinopel, Thessalonike oder zeitweise Nikaia, haben mehr als eine Pfarre bzw. einen pfarrähnlichen Kirchensprengel, sondern auch mittelgroße Städte, wie Trapezunt, Mistra oder Arta). Folglich liegt dieser Raumvorstellung eine begrenzte (Klein-)Landschaft, z. B. ein Tal, eine Insel oder eine Oase, zugrunde (und wirkt in ihren Dimensionen identitätsstiftend). Dies ist die persönlich, nicht nur intellektuell, sondern auch mit allen Sinnen wahrgenommene räumliche Ökumene.

Erweiterungen der subjektiven Ökumene können - jedenfalls in Hinblick auf den byzantinischen Kulturraum - generell den im folgenden behandelten Aspekten der Ideologie und der Religion, der Politik und der Bildung zugeordnet werden. Die Konkretisierung einer Erweiterung erfolgt im Alltag zumeist im Rahmen individueller, aktiv oder passiv erlebter Informationserfahrungen. Unter die aktiv erlebten Erfahrungen sind Reisen zu zählen, die man als Händler, Schiffer, Soldat oder Pilger, jedenfalls aufgrund einer Notwendigkeit (kaum einmal als Vergnügungs- oder Erholungsreisender, also als „Tourist") in bewußter Auseinandersetzung mit dem bereisten Gebiet, seinen Phänomenen und seinen Bewohnern unternimmt, wobei man eine Erweiterung der Ökumene unmittelbar selbst erlebt und wahrscheinlich auch am Reiseziel wiederum Mitteilungen über weitere Orte erhält (wodurch man mittelbar seine Ökumene nochmals erweitert) ${ }^{7}$.

5 Zur Entwicklung des griechischen Begriffes $\pi \alpha \tau \varrho i \varsigma(\pi \alpha \tau \varrho i \delta \alpha)$ vgl. Anna Moutafidou, Von der „aufgeklärten Vaterlandsliebe“ zum „privilegierten Patriotismus“: Zur Entwicklung und Veränderung politischer Begriffe im Griechenland des 19. Jahrhunderts. Mit einem Anhang von Sergios E. Katsikas, in: Anzeiger der phil.-hist. Kl. der Österr. Ak. d. Wiss. 136. Wien 2001, 177-198, hier $183 \mathrm{ff}$.

6 Von einer „wirklich erlebbaren engeren Heimat" spricht in diesem Zusammenhang E. PITz, Die griechisch-römische Ökumene und die drei Kulturen des Mittelalters. Geschichte des mediterranen Weltteils zwischen Atlantik und Indischem Ozean, 270-812 (Europa im Mittelalter, Abhandlungen und Beiträge zur historischen Komparatistik, hg. v. M. Borgolte, 3). Berlin 2001, 25. - E. BusEK, Heimat erwirbt man sich, zeit-schritt 11 (2002) 3, betont in diesem Zusammenhang die Komponenten sinnlicher und emotionaler Erfahrung.

7 Zu Pilger- und Reiseberichten: Voyage, quête, pèlerinage dans la littérature et la civilisation médiévales. Colloque du C.U.E.R.M.A., 5.-7. 3. 1976. Aix en Provence 1976; C. 
Passive Informationssituationen ergeben sich, abgesehen von schriftlichen Quellen, durch Berichte von Fremden, beispielsweise im Rahmen von Wochenmärkten oder Handelsmessen, von reisenden Händlern, aber auch von (berufsmäßigen?) Geschichtenerzählern und Liedersängern, wie denjenigen, die Arethas von Kaisareia (um 900) in einem Scholion erwähnt: „die Umgeher, für die als jetzt aktuelles Beispiel die verflixten Paphlagonier dienen mögen, denn sie erdichten irgendwelche Lieder, die die Leiden berühmter Männer zum Inhalt haben, und singen sie für einen Groschen vor jedem Haus" ${ }^{\text {" }}$.

Hinzu kommen literarische oder literaturnahe Informationen, für die man eine regelmäßige Verbreitung durch Vorlesung, Rezitation oder vorlagennahe Erzählung annehmen kann, also etwa hagiographische Texte, die im Kloster während der Mahlzeit vorgetragen wurden, aber auch andere Texte der „Volksliteratur“ 9 , die genrespezifisch eine - tatsächliche oder vermeintliche - Vertrautheit mit bestimmten Landschaften als „Schauplätzen“ anboten. Als Beispiele nenne ich die Apophthegmata Patrum für Ägypten, manche Pilgerberichte für die heiligen Stätten Palästinas und des Sinai, die Liederkreise um Armuris, Digenis Akritas und den Sohn des Andronikos für das „Sarazenenland" (vorzugsweise das Euphratgebiet im östlichen Kleinasien und in Syrien), Barlaam und Joasaph für „das innerste Äthiopien, das auch Indien heißt"10, und schließlich den byzantinischen Alexander-Roman ${ }^{11}$, mit dem man (ebenfalls) bis nach Indien gelangt.

\section{Politisch-Kaiserliche ÖKumene: Rom}

Die politische Ökumene der Byzantiner ist, über die in den Vorbemerkungen genannten Gründe hinaus, auch deswegen als Raum kaum einheitlich zu definieren, weil die Byzantiner sich ursprünglich in erster Linie mit der Institution des auf die Stadt Rom bzw. die Stadt Konstantinopel als das „neue Rom“ bezogenen Kaisertums in seiner jeweiligen Machtausdehnung identifizierten, und weniger mit einem Staatsterritorium ${ }^{12}$.

Galatariotou, Travel and Perception in Byzantium.DOP47 (1993) 221-241; A. Külzer, Peregrinatio graeca in Terram Sanctam. Studien zu Pilgerführern und Reisebeschreibungen über Syrien, Palästina und Sinai aus byzantinischer und metabyzantinischerZeit (Stud. u. Texte z. Byz., 2). Frankfurt a. M. 1994; E. TraPP, Aktualität in byzantinischen Reiseberichten, in: Chr. CoRmEaU (Hrsg.), Zeitgeschehen und seine Darstellung im Mittelalter/L'actualité et sa représentation au Moyen Âge. Bonn 1995, 47-58 (Sonderdruck); I. Ch. Dimitroukas, Reisen und Verkehr im Byzantinischen Reich vom Anfang des 6. Jahrhunderts bis zur Mitte des 11. Jahrhunderts, I-II(Historical Monographs 18). Athen 1997 (jeweils mit weiterer Lit.).

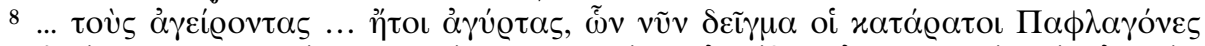

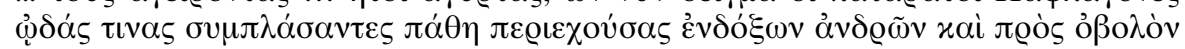

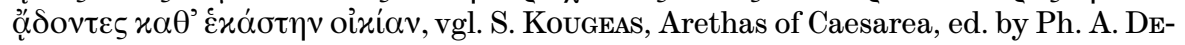
METRACOPOULOS. Athen 1985, $206 \mathrm{f}$.

9 Der Terminus gebraucht im Sinne von H.-G. BECK, Geschichte der byzantinischen Volksliteratur (Byz. Hdb. 2.3). München 1971.

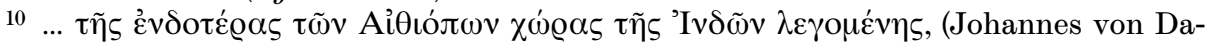
maskos,) Vita Barlaam et Joasaph, ed. G. R. Woodward / H. MatTingly. Cambridge Mass. 1914, Titel und ähnlich 4.26.

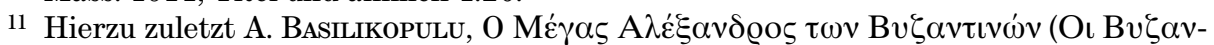

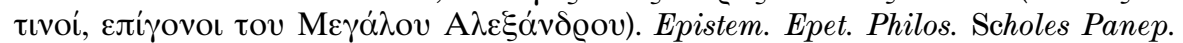
Athenon 32 (1998-2000) 413-426.

12 Vgl. die diesbezüglichen Überlegungen bei K.-P. MATschKe, Der Übergang vom byzantinischen Jahrtausend zur Turkokratie und die Entwicklung der südosteuropäi- 
Der machtpolitische Anspruch der Byzantiner auf Ökumenizität hat eine seiner Wurzeln in der römischen Makedoniermythisierung, der imitatio Alexandri Magni, und deren Überwindung in augusteischer Zeit: Bereits auf dem Triumphwagen, den der Senat 46 v. Chr. dem Jupiter Capitolinus weihte, ließ Julius Cäsar ein „bronzenes Abbild der Ökumene unter seinen Füßen“ dar-

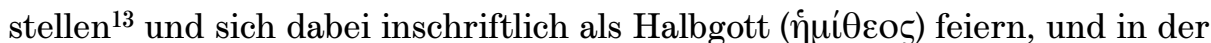
(um 10 n. Chr. datierten) Gemma Augustea umgibt sich Augustus / Jupiter mit Personifikationen des Okeanos und der Oikumene ${ }^{14}$. Dazu korreliert als Bestätigung des ökumenischen Anspruches durch den „Andern“, den Nichtrömer, daß Cassius Dio über Pyrrus berichtet, dieser habe nach seinem Sieg (280/ 279 v. Chr.) „die Römer, obgleich sie besiegt waren, bewundert und höher eingeschätzt als seine eigenen Soldaten, und dies mit den Worten begründet: Ich hätte mir bereits die ganze Ökumene untertan gemacht, wenn ich Herrscher der Römer wäre“15. Wie die Eroberung der Ökumene im römischen Kollektivbewußtsein (und späterhin bereits als normierende Gewohnheit) zu einem konstitutiven Element der Herrscherwürde in der Prinzipatszeit wurde, diese Entwicklung hat Giovanella Cresci Marrone aufgezeigt ${ }^{16}$, weshalb hier auf ihre Studie verwiesen sei.

Freilich ist oikumene nicht nur ein griechisches Wort, sondern ein spezifisch griechischer Terminus: In spätantiken Kaiserinschriften ${ }^{17}$ dominiert bei den räumlichen Herrschaftsattributen im Lateinischen orbis („Kreis“, „Erdkreis“), wo im Griechischen oikumene steht ${ }^{18}$. Die beiden Termini entsprechen einander natürlich nicht inhaltlich, aber in der Verwendung ${ }^{19}$.

schen Region. Jahrbücher für Geschichte und Kultur Südosteuropas 1 (1999) 11-38, hier bes. $12 \mathrm{f}$. und $16 \mathrm{f}$.

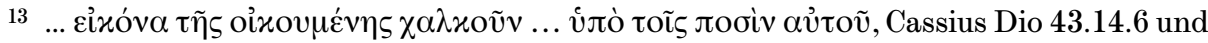
43.21.2 (II 80, 85 Boissevain), vgl. G. Cresci Marrone, Ecumene Augustea. Una politica per il consenso (Problemi e ricerche di storia antica. Rom 1993, 181.

14 P. Zanker, Augustus und die Macht der Bilder. München 1987, $232 \mathrm{ff}$.; CREsci MarroNE 1993, 204 f. (Augustus wird im rechten Teil des oberen Registers als Jupiter dargestellt).

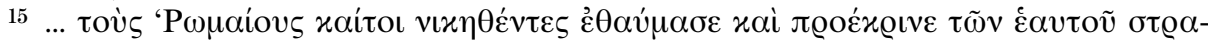

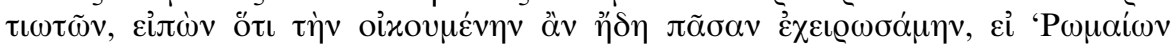

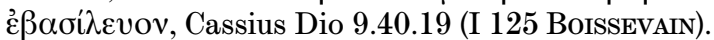

16 Cresci Marrone 1993, $269 \mathrm{ff}$., bes. 275.

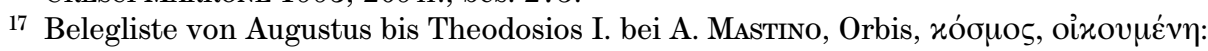
aspetti spaziai dell'idea di impero universale da Augusto a Teodosio, in: Da Roma alla terza Roma, III: Popoli e spazio romano tra diritto e profezia. Neapel 1986, 63-162, hier 147-156. Für christliche Kaiser gibt es allerdings insgesamt lediglich zwei In-

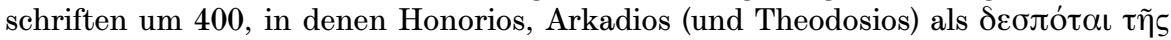

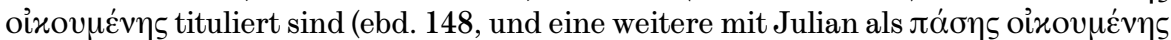

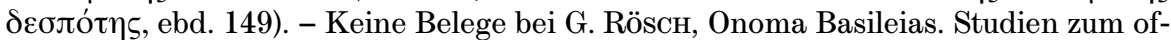
fiziellen Gebrauch der Kaisertitel in spätantiker und frühbyzantinischer Zeit (Byzantina Vindobonensia 10). Wien 1978, $159 \mathrm{ff}$.

18 Mastino 1986, $122 \mathrm{ff}$.; C. Molè, La terminologia dello spazio romano nelle fonti geografiche tardoantiche, in: Da Roma alla terza Roma, III: Popoli e spazio romano tra diritto e profezia. Neapel 1986, 321-350, hier 326. - Die Kaiser werden in dieser In-

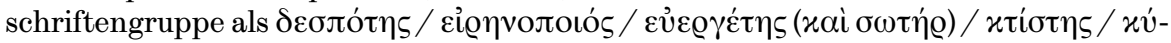

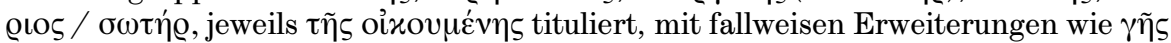

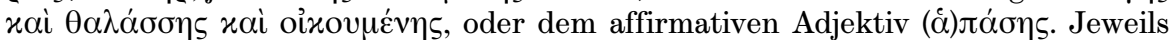

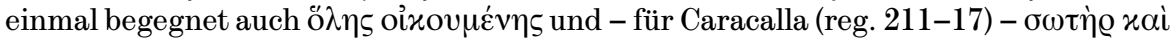

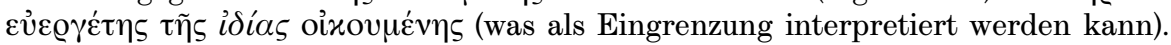

19 Die frühbyzantinische Westgrenze des Verbreitungsgebietes der griechischen in-

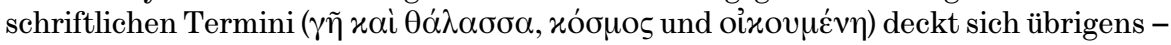
sieht man von einigen stadtrömischen Inschriften ab - gemäß der Karte bei MAsTino 1986, nach 156, exakt mit der Grenze der „theodosianischen Reichsteilung“. 
Eine Schlüsselfigur für das Verständnis des römisch-byzantinischen Ökumene-Denkens ist wohl Strabon. Johannes Engels hat Strabon als den „extremen Apologeten der römischen bellum iustum-Theorie“ bezeichnet, der eine „unbestreitbare Legitimität der römischen Ökumeneherrschaft in den Grenzen des augusteischen Reiches vorausgreifend schon zu Beginn des 2. Jahrhunderts vor Christus" vorausgesetzt habe; Strabon habe weiters das römische Ökumenereich in seiner Dimensionierung von Spanien über Karthago, Ägypten bis nach Griechenland, Kleinasien und Armenien gerechtfertigt. Was sich jenseits der Grenzen der römischen Ökumene befinde, sei einer Eroberung und der Einbeziehung in das Friedensreich des Augustus eben nicht wert $^{20}$. Strabons Gedankengut wird in seiner Konformität mit den Res gestae des Augustus ${ }^{21}$ und mit der ideologischen und politischen Propaganda seiner Zeit von der Geschichtsschreibung und von christlichen Texten der frühbyzantinischen Zeit aufgegriffen und als Ergebnis und Erfolg des Erscheinens Christi in der Ökumene bewertet: Deutlich wird dies schon im Weihnachtsevangelium und im liturgischen Formular des 25. Dezember (Vesper und Matutin) ${ }^{22}$, weiters in Kirchenvätertexten, etwa bei Theodoretos von Kyrros: „Just zur Zeit der rettungbringenden Niederkunft der Jungfrau ... ließ Augustus die gesamte Ökumene registrieren. Von da nahm die Wende von den Kriegen zum Frieden ihren Anfang“"23; und ähnlich bei Johannes Chrysostomos: „Nun ist der Großteil der Ö̉kumene in Frieden, alle können unbe-

20 J. Engels, Augusteische Oikumenegeographie und Universalhistorie im Werk Strabons von Amaseia (Geographica Historica 12). Stuttgart 1999, 298-313, die Zitate 305. S. bes. Diodorus Siculus, Hist. 12.26.2. - Differenzierter sah diese Grenzen schon Cassius Dio 53.12.4-7; vgl. auch dens., 44.2.4-5 über die Fehler der Caesar-Mörder, und

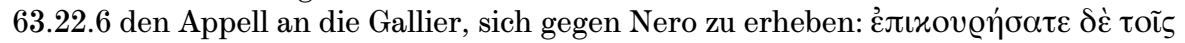

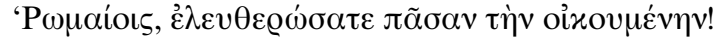

21 Vgl. hierzu ENGELs 1999, 353 ff.

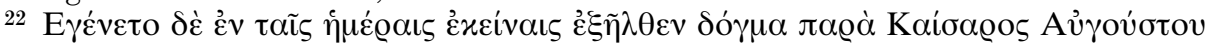

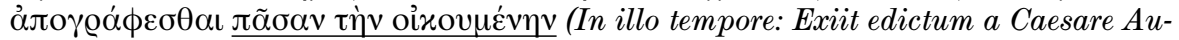

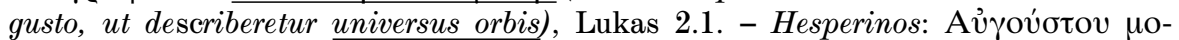

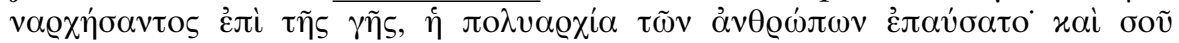

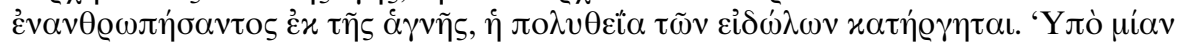

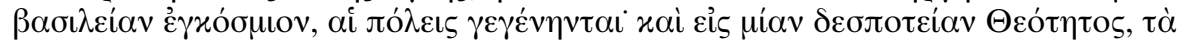

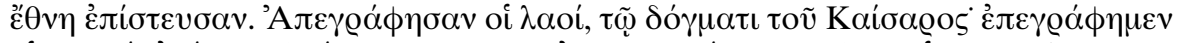

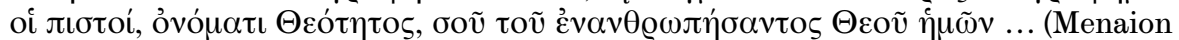

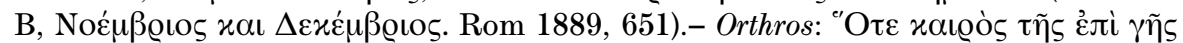

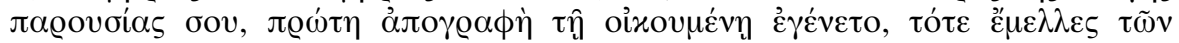

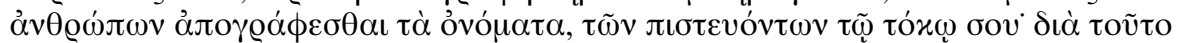

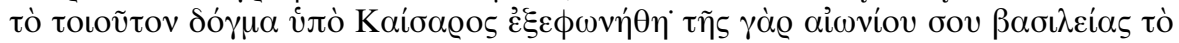

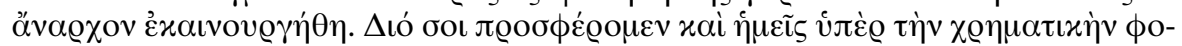

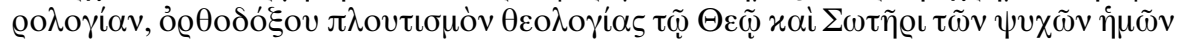
(ibidem 672).

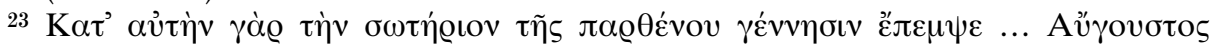

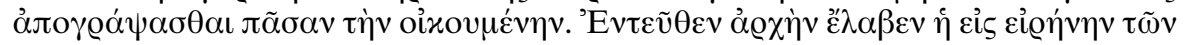
$\pi \circ \lambda \varepsilon ́ \mu \omega v \mu \varepsilon \tau \alpha \beta o \lambda \eta$, Theodoretos von Kyrros, Commentaria in Isaiam, ed. J.-N. GuINOT, II (SC 295). Paris 1982, $80 \mathrm{ff}$ - Ähnlich bei demselben, Interpretatio in Psalmos,

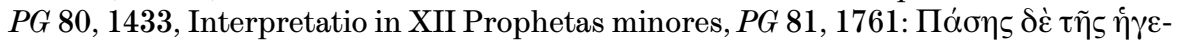

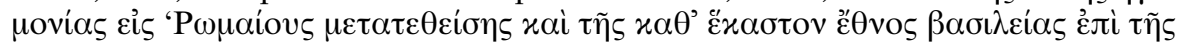

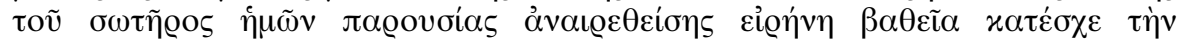

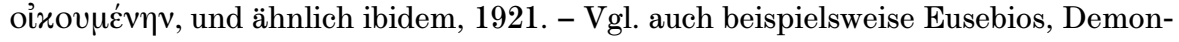
stratio evangelica, ed. I. A. Heikel, Eusebius Werke, 6: Die Demonstratio evangelica

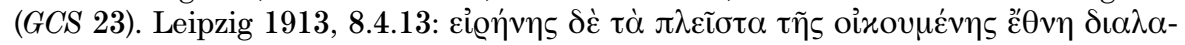

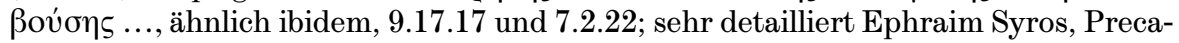

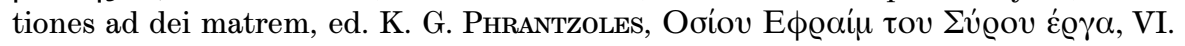
Thessalonike 1995, 364 . 
schränkt ihren Handwerken nachgehen, die Erde bearbeiten oder über das Meer segeln“24.

Die Verbindung der spätantiken Kaiserideologie mit dem Exklusivitätsanspruch des Christentums führt aber auch, beginnend spätestens mit Eusebios, zur weiteren Entwicklung der Raum-Zeit-Beziehung und zur diesbezüglichen Abgrenzung von der vorchristlichen Ökumene, ein Prozeß, der in nachjustinianischer Zeit unumkehrbar wird. Das Ende der „veralteten Zeit“ (der archaiotes, der Antike also) und der Beginn der christlichen „Neuzeit“ (die wir als Mittelalter bezeichnen) läßt die bisherige Geschichte zur „alten Geschichte" (archaiologia) - der Römer bei Dionysios von Halikarnass, der Juden bei Josephus Flavius - werden ${ }^{25}$ und bedingt (auch räumlich) eine Neuorientierung, über die noch zu sprechen sein wird.

\section{FrÜHChristLiche ÖKUMENE}

Ökumenizität ist also in den frühchristlichen Jahrhunderten bereits ein selbstverständlicher Dimensionierungsfaktor des römischen Reiches ${ }^{26}$. Was Ökumene, also die bewohnte, besiedelte Zone der Erde ist, definiert sich aufgrund der frühbyzantinischen Patristik vor allem durch ihr Gegenteil. Der eigentlich

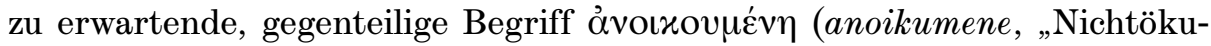
mene“) existiert allerdings in den Quellen (und Lexika) nicht. Der „klassische“

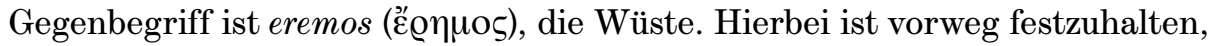
daß das heute geläufige inhaltliche Verständnis des deutschen Wortes „Wüste“ zu eng ist für eremos. Das Wort bezeichnet nicht unmittelbar nur das wasserlose und vegetationslose Land, sondern auch die „Wüstung“ und allgemein jede nicht von Kulturmenschen bewohnte Zone, also auch eine landwirtschaftlich nutzbare. Daher kann beispielsweise das besonders fruchtbare Quellgebiet des Pyramos, die von Lykandos beherrschte Elbistan Ovası in Kappadokien,

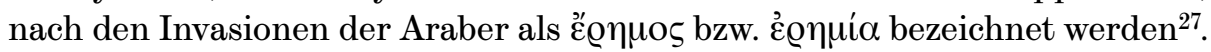

Aus demselben Grund beklagt Johannes Chrysostomos seinen landschaftlich schönen, wasserreichen und fruchtbaren (ebenfalls in Kappadokien gelegenen) Verbannungsort Kukusos in seinen Briefen oftmals, fast schon formelhaft wiederholend, als „wüsten, ja den wüstesten Ort in unserer Ökumene“28. In einem anderen Zusammenhang hebt Chrysostomos selbst aber die Vorzüge der Wüste hervor ${ }^{29}$ : „Die Wüste hat aber auch einen andern Nut-

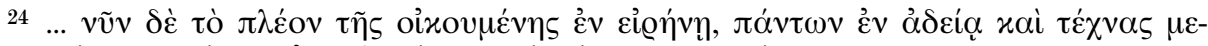

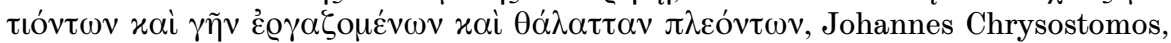
Expositiones in Psalmos, $P G$ 55, 207; vgl. auch dens., In Isaiam, ed. J. DumortiER (SC

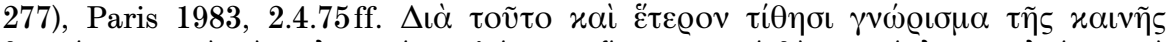

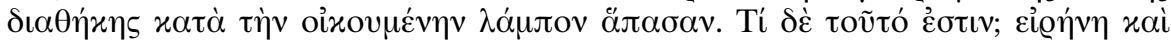

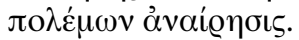

25 Vgl. hierzu J. KoDER, archaiologia und archaiotes. Zum „Ende der Antike“ aus byzantinischer Sicht (in Vorbereitung).

26 Vgl. J. Bentrvegna, The Times of the Christian Fathers: Theological Attempts at an Ecumenical Definition. Studia Patristica 15 (1984) 268-277.

27 Vgl. F. Hild / M. Restle, Kappadokien (Tabula Imperii Byzantini 2). Wien 1981, $224 \mathrm{f} ., 289,297$.

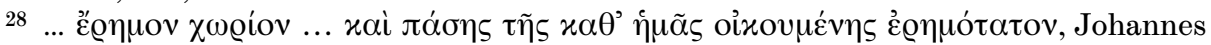
Chrysostosmos, Briefe, passim, z. B. PG 52,720; vgl. F. HiLD / M. Restle, wie A. 27, $217 \mathrm{f}$.

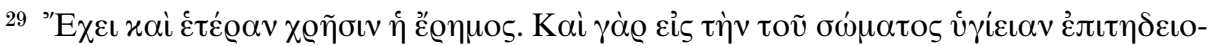

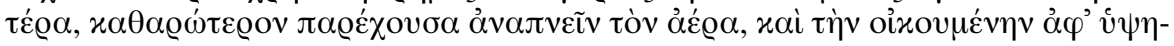


zen, und zwar ist sie für die Gesundheit des Körpers geeigneter, da sie gewährt, reinere Luft einzuatmen, und darüber hinaus, die gesamte Ökumene von der Höhe zu überblicken und in der Einsamkeit sich der Philosophie hinzugeben“. (Die hier speziell angesprochene, ökumenischen Überblick gewährende „Bergwüste“ spielt auf die Evangelienszene der Versuchung Jesu in der Wüste $a^{30}$; der Autor dachte aber wohl auch an die Anfänge des Mönchtums in der Wüste.)

In der antiken Literatur sind oikumene und eremos ein geläufiges Gegensatzpaar $^{31}$, in der Bibel begegnet der Gegensatz hingegen nur bei Isaias wört$\operatorname{lich}^{32}$. Im Rahmen der christlichen Deutung der Schöpfungsgeschichte gewinnt dann der Gegensatz wieder an Bedeutung: Nach Eusebios nannte Gott beim Schöpfungsakt den bewohnten Teil der Erde oikumene, um dadurch die

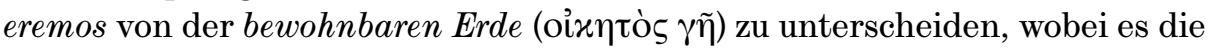
Rolle der Menschheit ist, als „die Besatzung der Ökumene“33 zu fungieren. Auch das Meer kann in diese Gliederung insoferne einbezogen werden, als „die Ungeheuer das Meer außerhalb der bewohnten Räume, dort also, wo es insellos ist, in Besitz genommen haben" 34 . Grundsätzlich ist auch das insellose „äußere Meer“ (die $\left.\iota^{\prime} \xi \omega \theta \alpha \dot{\lambda} \lambda \alpha \sigma \sigma \alpha\right)$ „Wüste“, denn beide sind „unendlich“

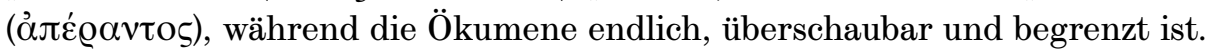
(Somit konnte man das allseits begrenzte und von besiedelten Inseln bedeckte Mittelmeer, und ganz besonders die Ägäis, zur Ökumene zählen.)

Das Christentum konnte - bildlich gesprochen und als glaubensimmanente Realität - die Wüste in Ökumene verwandeln. Dies geschah bereits durch Johannes den Täufer ${ }^{35}$, nach dem alttestamentarischen Vorbild des Propheten Elias ${ }^{36}$. Der Täufer predigte ja (nach Johannes Chrysostomos) bewußt „in der Wüste, nicht in der Ökumene, denn wüst war der Menschen Zustand, noch nicht bewohnt vom Vater und vom Sohn und vom heiligen Geist“"37. Entsprechend seinem Vorläufer gilt dann Christus als derjenige, der „der unbewohnbaren Wüste die Ökumene gegenüberstellt“"38, und späterhin

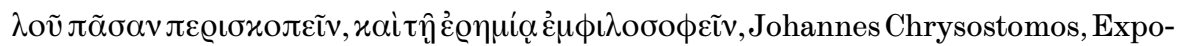
sitiones in Psalmos, PG 55, 123.

30 Mat 4.8f., Luk $4.5 \mathrm{ff}$.

31 Hier nur ein spätantikes Beispiel: Der alexandrinische Rhetor (Aelius) Theon (Wende 1./2. Jahrhundert n. Chr.) gibt in seinen Progymnasmata folgenden Hinweis für den

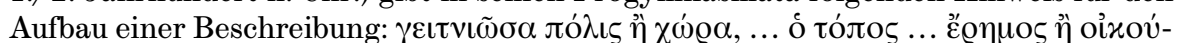

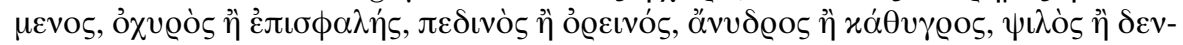

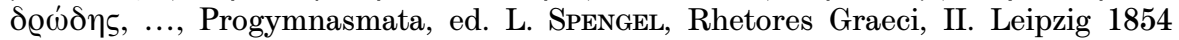
(Frankfurt am Main 1966), 79.

${ }^{32}$ Isaias 13.9, 14.7, 24.1, 62.4. - Keine Belege im Neuen Testament.

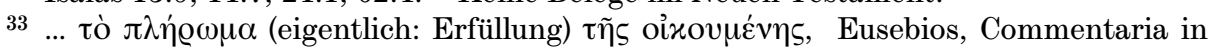
Psalmos, $P G 23,1092$

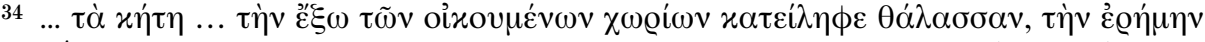

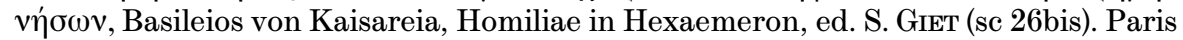
$1968,7.4$.

35 So Didymus Caecus, Fragmenta in Psalmos (e commentario altero), ed. E. MüHLENBERG, Psalmenkommentare aus der Katenüberlieferung, I (Patristische Texte und Stu-

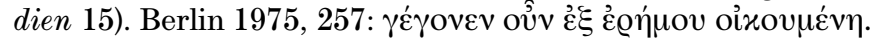

36 Theodoretos von Kyrros, Epistulae, Collectio Sirmondiana, ed. Y. AzÉma (SC 98). Pa-

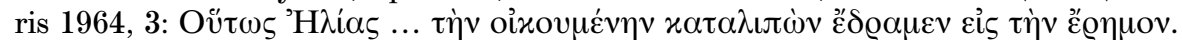

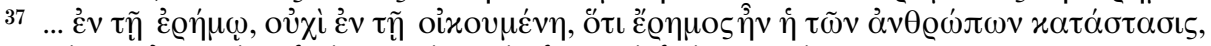

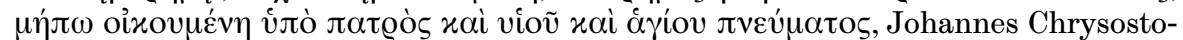
mos, Homilia in praecursorem domini, $P G$ 59, 490, unter Berufung auf Mat 3.1.

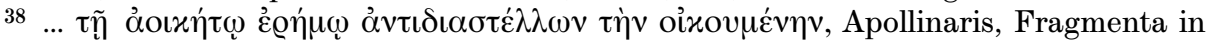
Matthaeum (in catenis), ed. J. REuss, Matthäus-Kommentare aus der griechischen Kirche (Texte und Untersuchungen 61), Berlin 1957, 124. 
sind es „die heiligen Märtyrer“, die „die Ökumene beschützen, die Städte heiligen, die Wüsten zu Städten machen und die Länder segnen“"39.

Diese Überlegungen trugen in der Zeit nach den Christenverfolgungen dazu bei, daß die Mönche die Rolle der Märtyrer übernahmen ${ }^{40}$ - Theodoros Studites sagt einmal, auch mit Worten spielend, von einem Mönch, er sei „der Stadtbürger der Wüste und der Erleuchter der Ökumene"41, wobei erneut das Vorbild des Johannes des Täufers zum Tragen kommt, der von Johannes Chrysostomos - in Unterscheidung von dem „Lehrer der Ökumene“ Paulus als „Stadtbürger der Wüste" bezeichnet wird ${ }^{42}$.

Der Gegensatz Wüste - Ökumene wurde im übertragenen Sinn auch auf die Seelen bezogen: Schon Origenes unterscheidet zwischen der „wüsten

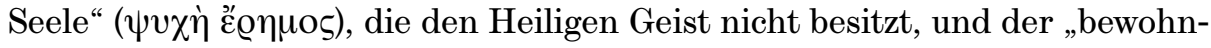

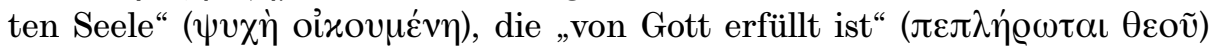

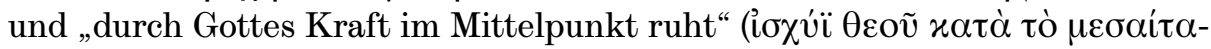

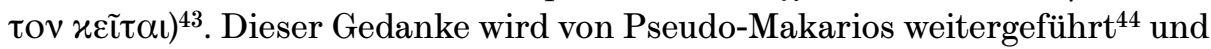
von Ephraim dem Syrer noch ausgebaut ${ }^{45}$.

\section{Eschatologische ÖKumene}

In Byzanz konkurrieren bekanntermaßen, über die Jahrhunderte hinweg mit manchen Modifikationen, die geographischen Konzepte, die sich aus der heidnischen Antike herleiten, mit denen aus der biblischen Schöpfungsgeschichte $^{46}$. Dies verdeutlichen (polarisierend) zwei ideologische Widersacher

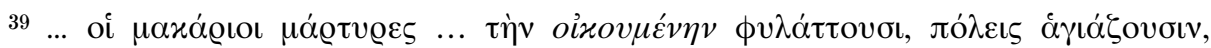

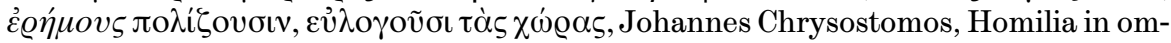
nes sanctos, ed. K. I. Dyobouniotes, Ekklesiastikos Pharos 9 (1912) 303-305, hier 304.

$40 \mathrm{Vgl}$. hierzu zuletzt N. ŠvčEnKo, The Hermit as Stranger in the Desert in: Strangers to Themselves: the Byzantine Outsider. Papers from the Thirty-second Spring Symposium of Byzantine Studies, University of Sussex, Brighton, March 1998, edited by Dion C. Smythe (Society for the Promotion of Byzantine Studies, Publications 8). Aldershot, Ashgate Variorum 2000, 75-86.

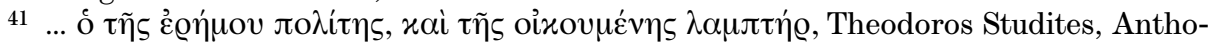
logiae Graecae Appendix, ed. E. Cougny, III, Paris 1890, 278: Brief an die Mönche der Chariton-Laura.

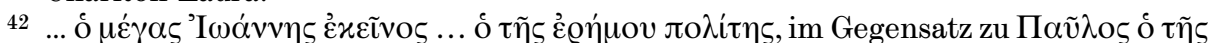

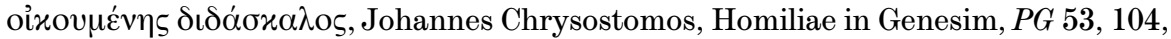

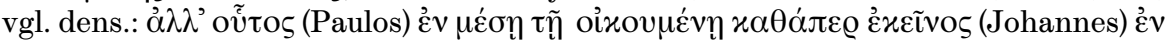

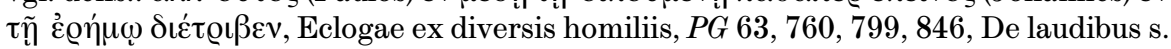
Pauli ap., ed. A. PiÉdagnel (SC 300). Paris 1982, 1.14.

43 Origenes, In Jeremiam, ed. P. NAUTin (SC 232). Paris 1976, 8.1. Vgl. auch Origenes, Selecta in Psalmos (Dub.), PG 12, 1265 und Exerpta in Psalmos (Dub.), $P G$ 17, 113: ‘ै $v$

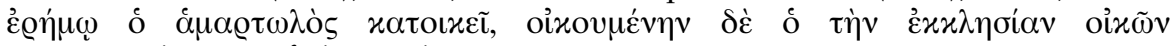

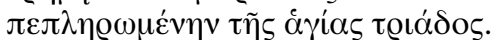

44 Pseudo-Makarios, Homiliae 7, ed. G. L. MARIotT, Macarii anecdota (Harvard Theolo-

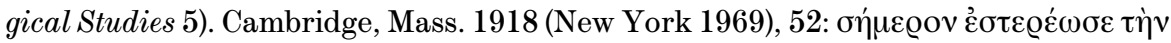

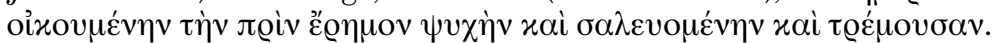

45 Ephraim Syros, Sermones ad monachos Aegypti, ed. K. G. Phrantzoles, Oóíov

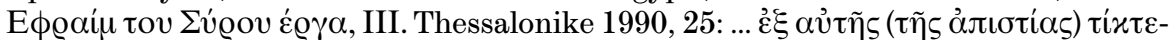

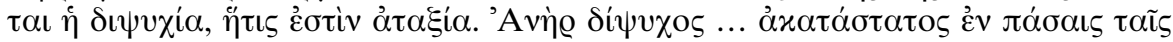

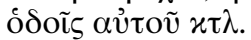

46 Vgl. allgemein J. KoDER, Soppravvivenza e trasformazione delle concezioni geografiche antiche in età bizantina, in: Geografia storica della Grecia antica. Tradizioni e Problemi, ed. F. Prontera (Bibl. di Cultura Moderna, 1011). Bari 1991, 46-66. - Für den byzantinischen Oikumene-Gedanken steht bei jedem „Erdmodell“ das theologisch begründete Festhalten an einer traditionellen, hierarchischen Ordnung fest. Ružena Do- 
im 6. Jahrhundert, Kosmas Indikopleustes und Johannes Philoponos. Die antoikumene hatte im biblischen Modell des Kosmas Indikopleustes keinen Platz $^{47}$ : Diese, so sagt er, habe niemals jemand gesehen noch davon gehört; hingegen hätten einige der alten Philosophen „die Ökumene bereist und ganz ähnlich wie die göttliche Schrift beschrieben" ${ }^{48}$. Johannes Philoponos, Olympiodor (unter Berufung auf Herodot) und andere stimmen dem Kosmas nicht $\mathrm{zu}^{49}$, wobei Olympiodor spezifiziert, daß lediglich die Seelen in dem in Europa und Asia unterteilten kosmos dem Gericht Gottes unterworfen würden, nicht aber diejenigen der antoikumene ${ }^{50}$. Diese Autoren stehen in der spätantiken Tradition, etwa des Ptolemaios, des Porphyrios und des Achilleus Tatios ${ }^{51}$, wonach die antoikumene durch den Nil mit der Ökumene verbunden sei, da „die Ursprünge des Nil in der antoikumene liegen“52. So kann Eusebios unter Berufung auf die ihm bekannten geographiai zu dem Schluß gelangen, daß die Verkündigung des christlichen Glaubens und die Kirche ,nicht in der antoikumene Verbreitung gefunden hätten, sondern lediglich die Seiten des Nordens und die nördliche Ökumene insgesamt erfüllt" hätten ${ }^{53}$.

Diese „ökumenischen“ Überlegungen sind als Bestandteil der Eschatologie-Debatte zu sehen: Beruhend auf Hinweisen des Alten und des Neuen Testaments $^{54}$, die Endzeit werde hereinbrechen, wenn der christliche Glaube überall auf Erden verkündet sei, prüfen christliche Schriftsteller seit dem 4. Jahrhundert, wie weit die Verkündigung bereits gediehen sei ${ }^{55}$. Dann näm-

stálová hat in diesem Zusammenhang auf Dionysios Areiopagites hingewiesen, „der die Welt als Ordnung ( $\tau \dot{\alpha} \xi ı \varsigma$ ) auffaßte ..., die unverändert in außerzeitlicher Ewigkeit fortdauert... Der Begriff $\tau \alpha \dot{\xi} \xi \varsigma$ ging dann auch in die Staatsideologie des byzantinischen Reiches über, dessen hierarchische Ordnung als vollendetes Bild der himmlischen und kosmischen Ordnung aufgefaßt wurde“, vgl. R. Dostálová, Das Ideal der Stasis gegenüber der Kinesis in der byzantinischen Weltanschauung (Der Fall des idealen antiken und byzantinischen Porträts). Acta Univ. Carol., Philolog. 3 / Graecolatina Pragensia 16-17

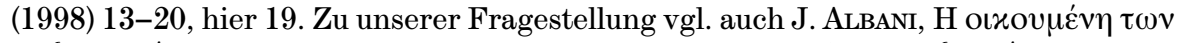

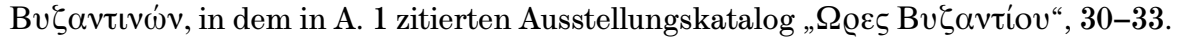

47 Kosmas Indikopleustes, Topographia Christiana, ed. W. WolskA-Conus, Cosmas Indicopleustes. Topographie chrétienne (SC 141, 159, 197). Paris 1968-1973, 2.65: ...

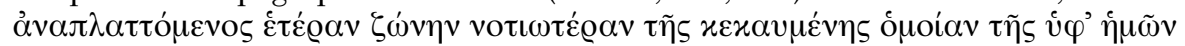

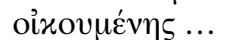

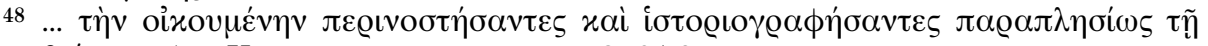
$\theta \varepsilon i \alpha$ $\gamma \varrho \alpha \phi \tilde{n}$, Kosmas Indikopleustes, a. O. 2.78

49 Johannes Philoponos, De opificio mundi, ed. W. Reichardt. Leipzig 1897, 169, Olympiodoros, In Aristotelis categorias commentaria, ed. G. STüvE (Commentaria in Aristotelem Graeca 12.2). Berlin 1900, 94 und 109. - Auch Photios, Bibl. 36 (I 21 f. HenRY), wendet sich gegen Kosmas und verteidigt die Kugelgestalt der Erde.

50 Olympiodoros, In Platonis Gorgiam commentaria, ed. L. G. WesterinK. Leipzig 1970, 49.

51 Ptolemaios, Geographia, ed. K. Müller. Paris 1883, 1.8.1 und 1.9.4, Porphyrios, Quaestionum Homericarum ad Odysseam pertinentium reliquiae, ed. H. ScHRAdER. Leipzig 1890, 3.295, Achilleus Tatios, Leucippe et Clitophon, ed. E. VILBorg. Stockholm 1955,30 .

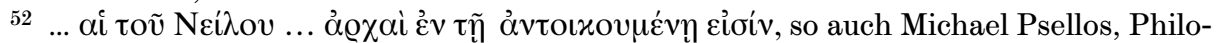
sophica minora, ed. J. M. DufFY. Leipzig 1992, 20.78 (Zum Ursprung des Nil vgl. Herodot, Hist. 2.17,28,33f.).

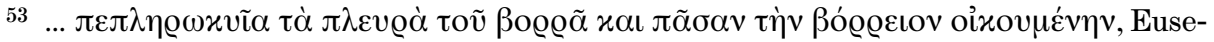
bios, Commentaria in Psalmos, $P G$ 23,421

54 Altes Testament: Ps 9.9, 95.13 u.ö., Is 13.9 u.ö., Dan 3. - Neues Testament: Mat 24.14, Luk 21.26, APG 17.31, Apok 3.10 et passim.

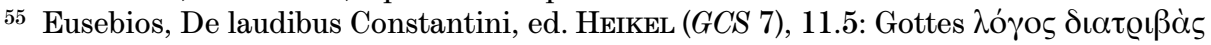

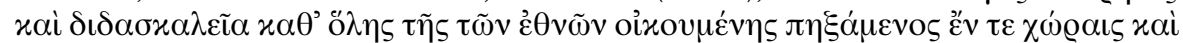

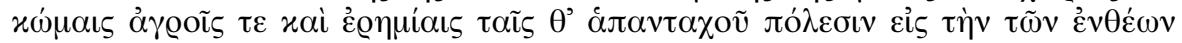


lich werde Gott, anläßlich des Jüngsten Gerichtes, die Ökumene wieder zur Wüste machen: „Unabwendbar in Wut und Zorn kommt der Tag des Herrn, um die gesamte Ökumene zur Wüste zu machen und die Sünder aus ihr auszurotten" ${ }^{“ 6}$. Höhepunkte der Endzeiterwartung waren dann bekanntlich die Jahrtausendwenden nach der alexandrinischen bzw. der byzantinischen Ära, also die Zeit um die Jahre 500 und 1500 christlicher Zeitrechnung ${ }^{57}$.

\section{Politisch-Kaiserliche ÖKumene: Byzanz vor den Kreuzzügen}

Doch zurück zur politischen Ökumene: Wie bereits festgestellt, galt Augustus zur Zeit von Christi Geburt als der gefeierte Friedensherrscher. Doch war es nur eine Frage der Zeit, daß die Rolle des ökumenischen Friedensfürsten auf Konstantin den Großen überging ${ }^{58}$, der selbst durch den (Neu-)Bau der Hagia Eirene, der Kirche des Friedens Christi ${ }^{59}$ an dieser Charakterisierung mitgewirkt hatte. Zitiert sei die Feststellung des Alexandros Monachos (6./9. Jahrhundert?): „Als der große Konstantin Alleinherrscher geworden war, da lag die Ökumene in tiefem Frieden ..."60. In dieser Tradition stehen später, bei-

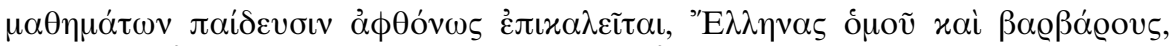

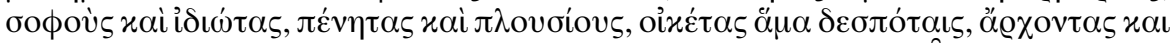

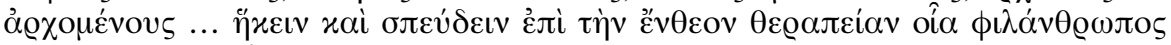

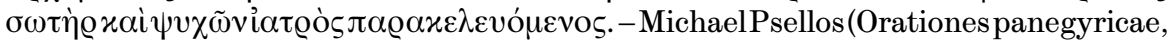
ed. G. T. DenNIs. Stuttgart 1994, 17.623ff.) verweist darauf, daß der Apostel Paulus $\mu \grave{\eta}$

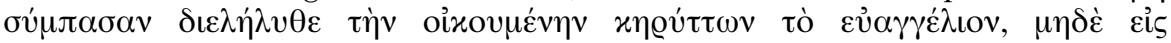

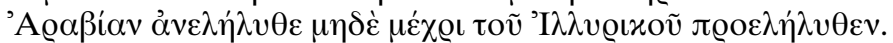

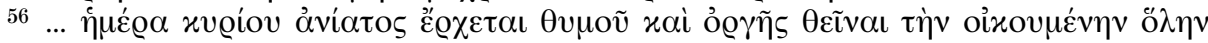

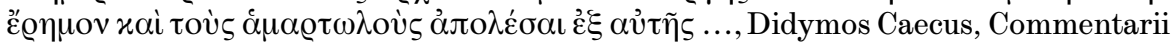
in Zacchariam, ed. L. DoutreleAu, Didyme l'Aveugle sur Zacharie, (SC 83, 84, 85). Paris 1962, 5.22; ähnlich Theodoretos von Kyrros, Commentaria in Isaiam, a. O. 5 et passim, natürlich Kosmas Indikopleustes, a. O. 5.128 und 7.40, aber auch Johannes von Damaskos, Sacra parallela, $P G$ 95, 1156 et passim, Kyrillos v. Alexandreia, Commen-

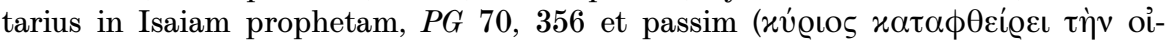

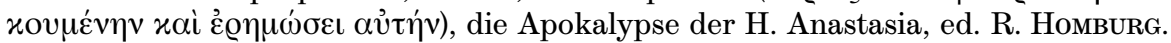

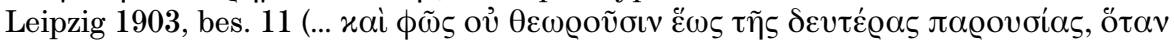

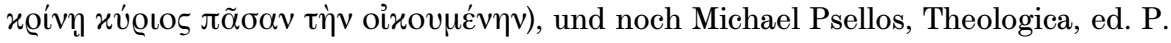
GAUTIER. Leipzig 1989, $48.92 \mathrm{ff}$.

57 Beginn der alexandrinischen Ära: 5500/1 oder 5491/2 v. Chr., der byzantinischen Ära: 5508/9 v. Chr. - Vgl. zur Endzeiterwartung bes. P. Magdalino, The history of the future and its uses: prophecy, policy and propaganda, in: The Making of Byzantine History. Studies dedicated to Donald M. Nicol, ed. R. Beaton und Ch. Roueché. Aldershot 1993, 3-34, und G. Podskalsky, Byzantinische Reichseschatologie. Die Periodisierung der Weltgeschichte in den vier Großreichen (Daniel 2 und 7) und dem tausendjährigen Friedensreiche (Apok. 20). Eine motivgeschichtliche Untersuchung. München 1972; weiters A. VASILIEv, Mediaeval Ideas of the End of the World. Byzantion 16 (1942/43) 462-502; B. E. DALEY, Apocalypticism in Early Christian Theology, in: The Encyclopedia of Apocalypticism I. New York 1999, 3-47, und D. OLsTER, Byzantine Apocalypses, ebd. 48-73 (jeweils mit weiterer Lit.).

58 Vgl. R. LeEB, Konstantin und Christus. Die Verchristlichung der imperialen Repräsentation unter Konstantin dem Großen als Spiegel seiner Kirchenpolitik und seines Selbstverständnisses als christlicher Kaiser (Arbeiten zur Kirchengeschichte 58). Berlin / New York 1992.

59 Sokrates, Kirchengeschichte 1.16.2 und 2.16.16 (54f. und 109 Hansen), vgl. L. Völkl, Der Kaiser Konstantin, Annalen einer Zeitenwende, München 1957, 164.

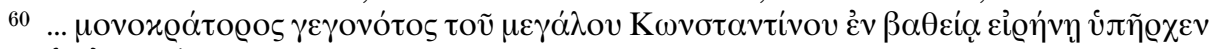

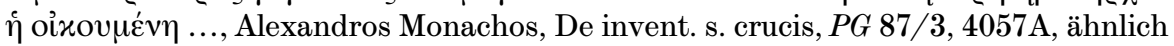
ebd. 4053B und 4057D/4060A. 
spielsweise, die Chroniken des Theophanes und des Georgios Monachos ${ }^{61}$. Auch Konstantinos Porphyrogennetos verweist in De thematibus erneut zusammenfassend auf die große Zeit, ,als die Kaiser mit dem Fußvolk zu Feld zogen ... und beinahe die gesamte Ökumene zu unterwerfen suchten, da sie ungeordnet und aufrührerisch war; diese Kaiser waren Julius Caesar, der wunderbare Augustus, jener hochberühmte Traian, ...", und er ergänzt im selben Satz die Reihe der Kaisernamen durch die christlichen „Vollender“: ,... sowie Konstantin, der Große unter den Kaisern, und Theodosios und alle, die nach jenen dem Christentum und der Gottesfurcht anhingen"62. In diesem Zusammenhang sei auf die deutliche Bezugnahme Konstantins VII. auf Konstantin den Großen hingewiesen, die erst in jüngeren Studien angemessene Berücksichtigung findet ${ }^{63}$.

Nun ist nicht mehr das von Erdbeben (262) und der nachfolgenden gotischen Plünderung (263) zerstörte Ephesos ${ }^{64}$ die „erste Adresse“ Roms im Osten, sondern für kurze Zeit Diokletians Nikomedeia und schließlich das einstige Byzantion, das nachkonstantinisch als neues Rom verstanden wird und wenigstens bis in das Frühmittelalter in gesamtmittelmeerischem Ökumene-Verständnis als Mittelpunkt verankert bleibt - außer Zweifel zur Zeit Justinians I. ${ }^{65}$ und noch über Herakleios hinaus: Hervorzuheben ist hier Konstans II. (641-668), der den ökumenischen Herrschaftsanspruch - aus seiner Sicht - sehr wohl zu wahren vermochte: im Osten durch den Vertrag mit Muawija (659) und im Westen durch seinen Kriegszug in die Sklabiniai (658) und durch seine teilweise erfolgreichen Kriege gegen die Langobarden in Italien ${ }^{66}$, woran sich der Besuch Roms (663) und die - in der byzantinischen Geschichte einzigartige - Niederlassung im Westen schloß. Er wählte Syrakus als neue

61 Theophanes, Chronographia, ed. C. DE Boor, I. Leipzig 1883 (Hildesheim 1963), 16 :

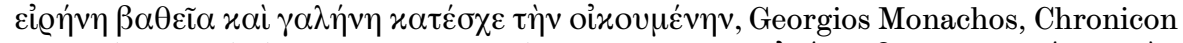

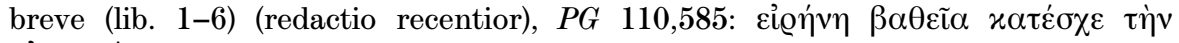

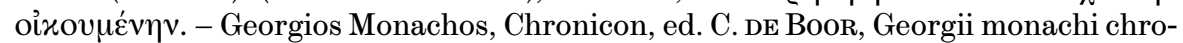
nicon, I. Leipzig 1904 (Stuttgart 1978), 296, und idem, Chronicon breve, PG 110,353, preist allerdings auch den Augustus-Frieden.

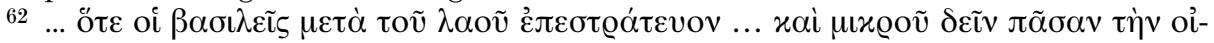

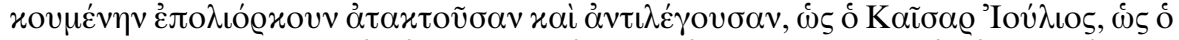

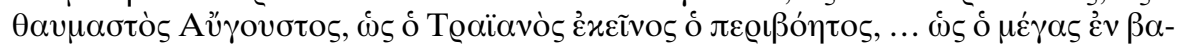

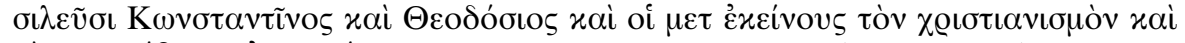

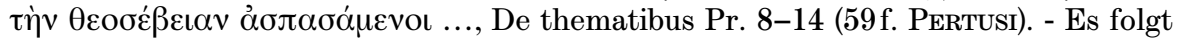

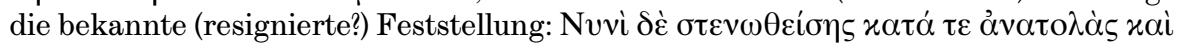

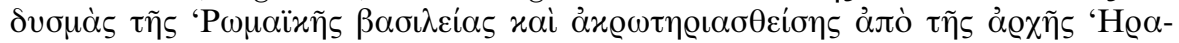

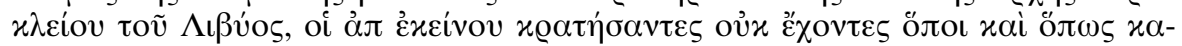

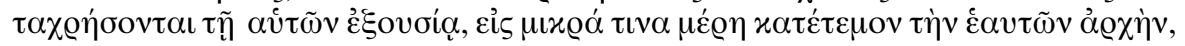
De thematibus Pr. 20-23 (60 Pertusi).

63 Vgl. besonders A. Markopoulos, Constantine the Great in Macedonian historiography: models and approaches, in: New Constantines. The rhythm of imperial renewal in Byzantium, $4^{\text {th }}-13^{\text {th }}$ centuries, ed. by P. Magdalino. Aldershot 1994, 159-170.

64 Zum Niedergang von Ephesos im ausgehenden 3. Jahrhundert vgl. S. LADSTÄTTER, Die Chronologie des Hanghauses 2, in: F. Krinzinger (Hrsg.), Das Hanghaus 2 von Ephesos. Studien zu Baugeschichte und Chronologie (Archäol. Forsch. 7 = Denkschriften phil.-hist. Kl. ÖAW 302). Wien 2002, 9-40, mit 87 Abb.

65 Zur Rechtfertigung seines gesamtökumenischen Herrschaftsanspruchs gegenüber dem Westen und dessen Durchsetzung im bellum justum vgl. D. BrodKa, Prokopios von Kaisareia und Justinians Idee „der Reconquista“. Eos 86 (1999) 243-255, bes. $253 \mathrm{f}$.

66 Vgl. P. ConsI, La politica italiana di Costante II. Settimane 34 (1988) 751-796, und PmbZ I/ II 480-485 (Nr. 3691). 
Residenz (wo er 668 ermordet wurde) ${ }^{67}$. Vielleicht sollte in diesem Zusammenhang auch noch die neunzeilige Versinschrift Erwähnung finden, die zu Ehren des Kaisers Theophilos (829-842) anläßlich der Erneuerung eines Bauwerkes (einer Kirche?) bei der Festung Tigani auf Samos angebracht wurde, denn sie akklamiert den Kaiser unter anderem mit den Worten ${ }^{68}$ :

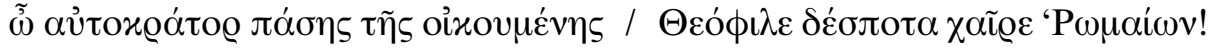

O Kaiser der gesamten Ökumene,

Theophilos (=Gottesfreund), Herrscher der Römer, sei gegrüßt!

Konstantinos Porphyrogennetos bezog seine geographischen Kenntnisse bekanntlich nicht von Ptolemaios, sondern von Strabon, den er mehrfach ausdrücklich zitierte ${ }^{69}$ und vielleicht in einem von Arethas von Kaisareia (oder von Photios?) kommentierten Exemplar benützte ${ }^{70}$. Einerseits war sich Konstantin einer „Verstümmelung“ der römisch-byzantinischen politischen Ökumene zu seiner Zeit bewußt, andererseits hielt er allerdings an der Herrschaft über die Meere bis zu den Säulen des Herkules und am prinzipiellen Anspruch auf Teile der italischen Halbinsel fest: Am Beginn des Kapitels über das Thema Sikelia hebt er hervor, es habe in Sizilien zu seiner Zeit im Vergleich mit dem antiken Rom sogar eine Erweiterung des östlichen Machtbereiches stattgefunden. Zwar „entwickelte sich nun diese schädliche Neuerung dadurch, daß Rom die Kaiserherrschaft abgelegt hat und eine Eigenherrschaft besitzt - es wird derzeit eigentlich von einem Papst beherrscht"71 _ aber „die überaus große und prachtvolle Insel Sizilien ... befindet sich nun unter der Hoheit Konstantinopels, da der Selbstherrscher von Konstantinopel das Meer bis zu den Säulen des Herkules und somit jedes hiesige Meer beherrscht" ${ }^{42}$. Die thalassokratia ${ }^{73}$ der Byzantiner über die Ökumene erweist sich somit als (verbal) gefestigt - man denkt hier auch an die kritische Bemerkung des Nikephoros Phokas gegenüber Liutprand von Cremona, wie sehr die

67 Sein gesamtmittelmeerischer Ökumenizitätsanspruch wird auch dadurch deutlich, daß er sich just in Sardinien (in Porto Torres) in einer Inschrift als $\delta \varepsilon \sigma \pi$ ó $\rceil \varsigma \tau \tilde{\eta} \varsigma$ ö $\lambda \eta \varsigma$

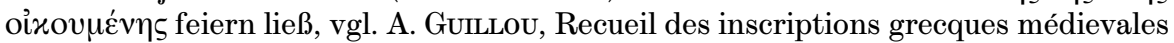
d'Italie (Coll. Ecole Fr. Rome, 222). Rom / Paris 1996, 243-246 (Nr. 230).

68 Edition von A. M. SchNeIDER, Samos in frühchristlicher und byzantinischer Zeit. Mitteilungen des dt. Archäol. Inst., Athener Abt. 54 (1929) 96-141, hier 101. - Zum Kaiser vgl. PmbZ I/IV 628-636 (Nr. 8167).

69 Z. B. De them. or. 2.5 (Pertusi).- Zu den geographischen Vorstellungen Konstantins

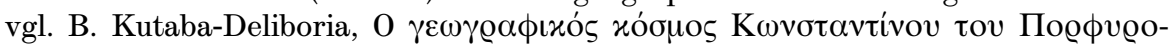

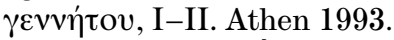

70 Vgl. F. LAsserRe, Étude sur les extraits mediévaux de Strabon, suivie d'un traité inédit de Michel Psellus. L'Antiquité Classique 28 (1959) 32-79, hier 70 ff.; A. Diller, The Textual Tradition of Strabo's Geography. With appendix: The Manuscripts of Eustathius' Commentary on Dionysius Periegetes. Amsterdam 1975, 80f.

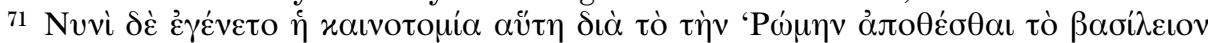

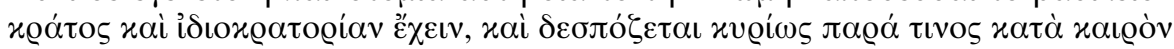

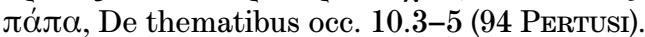

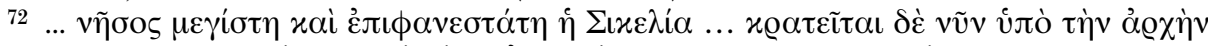

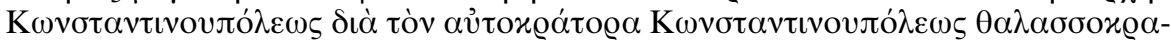

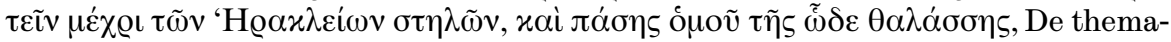
tibus occ. 10.5-7 (94 PeRTusi). - Man beachte die selbstverständliche Stadtbezogenheit der Kaiserherrschaft!

73 Vgl. allgemein J. KodER, Aspekte der thalassokratia der Byzantiner in der Ägäis, in: Griechenland und das Meer. Beiträge eines Symposions in Frankfurt im Dezember 1996, hrsg. v. E. Chrysos, D. Letsios, H. A. Richter, R. StupPerich (= Peleus. Studien zur Archäologie und Geschichte Zyperns, 4). Mannheim 1999, 101-109. 
byzantinische Flotte der ottonischen überlegen sei $^{74}$. Darüber hinaus, so Konstantin, festige sich in Italien die Herrschaft der Byzantiner auch zu Land,

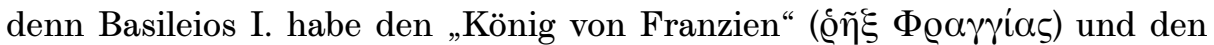
Papst von Rom zur Heerfolge aufgerufen und mit ihrer Hilfe Bari und „ganz Longibardia" von den Sarazenen zurückerobert ${ }^{75}$.

Die seit der Spätantike geläufigen Vorstellungen von der geographischen Erstreckung der „gesamten“ Ökumene kennt der Kaiser; daher erklärt er am Beginn von De thematibus - Anlaß ist die Darstellung des Themas Anatolikon -, daß dessen Name lediglich aus der Sicht derjenigen gerechtfertigt sei, die

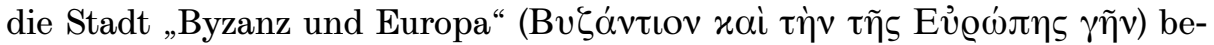
wohnen, und verweist auf die Inder, Äthiopier und Ägypter, für die dies beispielsweise nicht zutreffe ${ }^{76}$. Konstantinopel selbst behandelt er am Beginn des europäischen Teiles von De thematibus, also in der Mitte des Werkes, da es ,als kaiserlich regierende Stadt den gesamten Kosmos überragt“77. Der aktuelle Bezugspunkt ist seit dem 4. Jahrhundert das neue Zentrum bzw. die „neue Mitte“, um eine von Herbert Hunger aufgegriffene Formulierung des Theodoros Metochites zu verwenden ${ }^{78}$.

Die innere Gliederung der Ökumene in Themen bedeutet für Konstantin

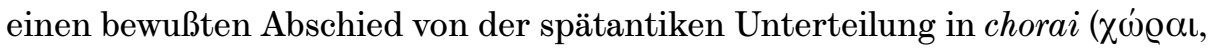
regiones, partes $)^{79}$, wie er sie in Hierokles' Synekdemos dokumentiert findet, den Konstantin ja verwendet hat ${ }^{80}$; damit wird auch die spätantike Überein-

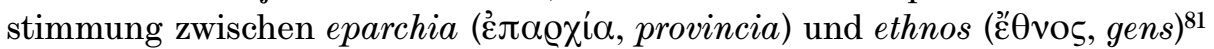
aufgegeben. In De thematibus steht außer Zweifel, daß sich sämtliche Provinzen (themata) innerhalb der byzantinischen Ökumene dieses „neuen Konstantin“ befinden. In De administrando imperio, dem „außenpolitischen Handbuch" für seinen Sohn Romanos, betont Konstantin VII. den ökumenischen Herrschaftsanspruch ebenfalls mehrfach: Schon im Prooimion betont der Kaiser die Bedeutung aller Informationen, in denen sich „Lage und Wettermischung des von ihnen (scil. den Völkern bzw. gentes) bewohnten Erdengebietes und dessen Beschreibung und Ausmaß" wiederspiegelt ${ }^{82}$. Neben den Ausführungen im Prooimion sei hier ein „Zwischenproöm“83 hervorgehoben, in

${ }^{74}$ Liutprand von Cremona, Relatio de legatione, c. 11.

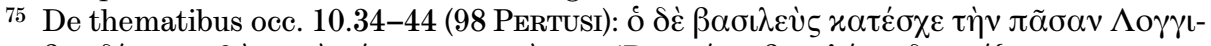

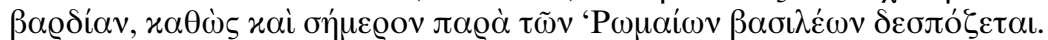

76 De thematibus or. 1.2-7 (60 PeRTusi).

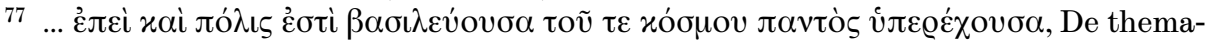
tibus occ. 1.2-7 (84 PeRTUSI).

78 H. Hunger, Reich der Neuen Mitte, wie A. 2.

79 C. Molè 1986, wie A. $18,343$.

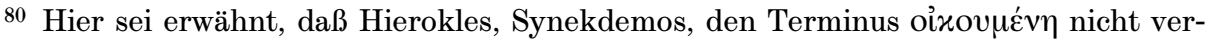
wendet.

81 C. MoLè 1986, wie A. 18, 344.

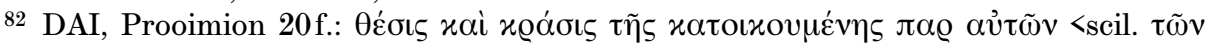

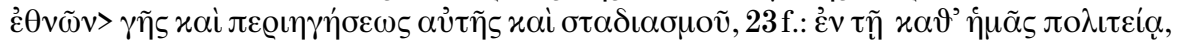

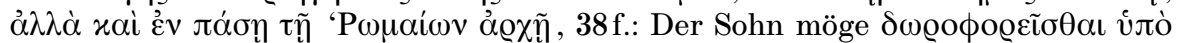

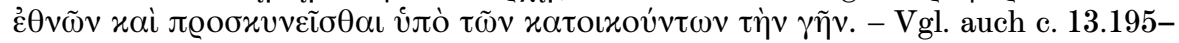

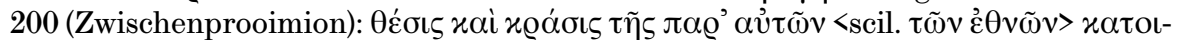

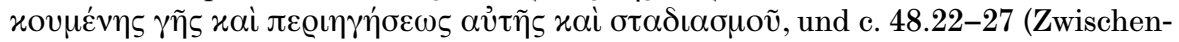

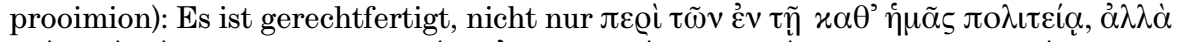

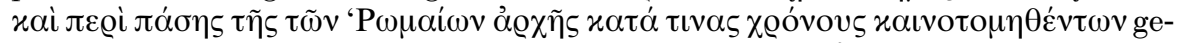

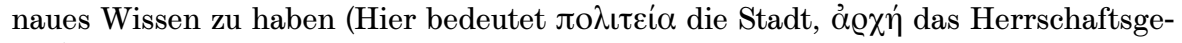
biet).

${ }^{83} \mathrm{Zu}$ dem Terminus und zur Gliederung des Werkes vgl. C. Sode, Untersuchungen zu De administrando imperio Kaiser Konstantins VII. Porphyrogennetos, in: Poikila By- 
dem er wünscht, sein Sohn möge „das Schiff der Welt“ ( ó $\lambda x \alpha ́ \delta \alpha$ ) steuern und leiten ${ }^{84}$. Der Kaiser (oder der von ihm beauftragte Autor) beschreibt in den wesentlichen Teilen von De administrando imperio in erster Linie Völker außerhalb der byzantinischen politischen Machtgrenzen. Zumeist wird dabei deutlich zwischen den Rom-Zugehörigen, den „Inländern“ einerseits, und den Auswärtigen ('ُ $\xi \omega \tau \iota x o i ́)$, den „Ausländern“, andererseits unterschieden ${ }^{85}$.

Die politischen Konzepte der makedonischen Dynastie werden seit einiger Zeit auf die konkrete und eingeschränkte Fragestellung nach begrenzter oder absoluter Ökumenizität hin untersucht ${ }^{86}$. Doch der Ansatz eines bewußten Abgehens von der „absoluten Ökumenizität“, im Sinne eines planvollen grundsätzlichen Wechsels der politischen Ideologie, der gewissermaßen von „offiziellen“ Politologen oder Staatstheoretikern gesteuert oder beeinflußt wird, scheint mir zu sehr von historiographischen Betrachtungsmöglichkeiten unserer Zeit, der Nachwelt, auszugehen, also zu modern gedacht. Eine Verwirrungsgefahr besteht $\mathrm{m}$. E. zudem darin, dem Terminus oikumene eine heute gerechtfertigte - oder jedenfalls vertretbare - ideologiepolitische Bedeutung auch für das 9. und 10. Jahrhundert zu unterlegen, obgleich diese Bedeutung in byzantinischen Quellen tatsächlich nicht erkennbar ist. - Wäre der Begriff Ökumene nicht auch so sehr byzantinisch, dann bestünde das Verwirrungsproblem nicht.

Für die Byzantiner stand die „selbstverständliche“ (auch unterbewußte) Identifikation mit den „Römern“ außer Zweifel; dies schon deswegen, weil sie aus einer auf die Gesamtherrschaft über die Ökumene geprägten Tradition heraus die Fragestellung als solche in ihrer Absolutheit nicht kannten. Die „verengte“ ökumenische Sicht des 10. Jahrhunderts beruhte nicht auf einer „Entscheidung“ der makedonischen Dynastie (bzw. einzelner ihrer Angehörigen), sie war vielmehr das - vorläufige - Ergebnis einer vielfältigen, vorange-

zantina 13 / Varia 5. Bonn 1994, 149-260, sowie J. Signes CodoÑER, El De administrando imperio de Constantino Porfirogeneto: Problemas de estructura y concepción de la obra. Salamanca 1989.

84 DAI, c. 1.4-15.

85 DAI, c. 43-46 (Allerdings werden hier manche Völker der kaiserlichen Einflußsphäre zugerechnet, die ihr zur Zeit der Abfassung [noch] nicht angehören, etwa die Armenier und die Georgier). - Die Schlußkapitel 47-53 stellen offenbar einen ungeordneten Anhang dar; zur Frage der Gliederung von DAI vgl. zuletzt K. Belke / P. Soustal, Die Byzantiner und ihre Nachbarn. Die De administrando imperio genannte Lehrschrift des Kaisers Konstantinos Porphyrogennetos für seinen Sohn Romanos (Byzantinische Geschichtsschreiber, 19). Wien 1995, 46-58.

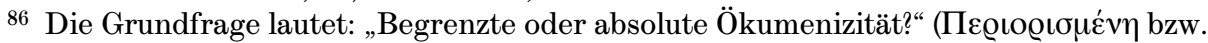

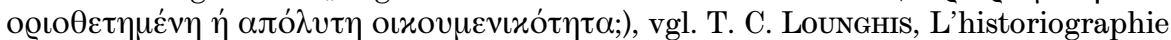
de l'époque Macédonienne et la domination byzantine sur les peuples du Sud-est Europeén d'après les traités de paix du IXe siècle. Balkan Studies 21 (1980) 69-86, vgl.

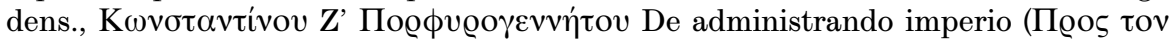

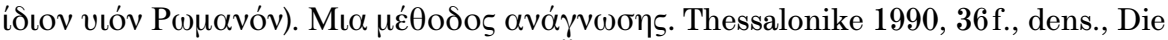
byzantinische Ideologie der „begrenzten Ökumene“ und die römische Frage im ausgehenden 10. Jahrhundert, in: Stephanos. Studia byzantina ac slavica Vladimíro Vavřinek ad annum sexagesimum quintum dedicata (= Byzantinoslavica 56). Prag 1995,

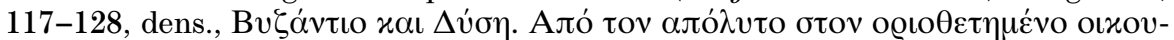

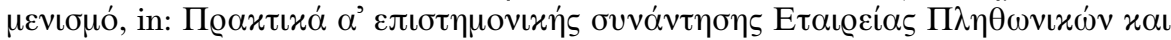

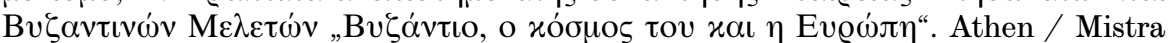
2001, 23-30, und dens., Byzantine political encounter concerning Eastern Europe (VXI centuries). Byzantina et Slavica Cracoviensia 3 (2001) 17-25, wo Verf. die Chazarenpolitik (seit Herakleios) in ihrem plötzlichen Wechsel unter Basileios I. und Leon VI. zusätzlich heranzieht, was seine Argumentationslage freilich nicht verbessert. 
gegangenen (und weiterhin im Fluß befindlichen) Entwicklung87. Damit nähert man sich einer Bewertung der flexiblen räumlichen Denkschemata der byzantinischen Politik und ihrer Veränderungen: Tatsächlich dürften die Kaiser und ihre maßgeblichen Amtsträger ab dem ausgehenden 6. Jahrhundert verstärkt von einer „ökumenischen“ Politik, die nicht mit den Maßstäben einer „normalen“ Außenpolitik gemessen werden kann, da sie dem Anspruch nach tatsächlich „alles“ inkludiert, übergegangen zu sein zu einer räumlich überschaubaren Außenpolitik, also einer regionalisierten „Nachbarschaftspolitik“; einer Politik also, die in erster Linie auf Nachbarn (gegebenenfalls unter Mitwirkung der Nachbarn der Nachbarn) ausgerichtet und nicht mehr „global“ konzipiert war ${ }^{88}$.

Dabei stand die ideologische Entwicklung mit der Entwicklung der politischen Leitlinien fortschreitend immer weniger im Einklang, ohne daß dies zu einem Dilemma geführt hätte (Die Realitätsbewältigung gelang für lange Zeit dank einer ideologischen „Schizophrenie“). Fast als hätte er dies vorhergesehen, formuliert schon Kaiser Justinian paradigmatisch den ökumenischen Anspruch der Kirche für jene Zeiten voraus, in denen politischer und kirchlicher Anspruch auf die Leitung der Ökumene nicht mehr übereinstimmen. So nimmt er in Novelle 109 auf alle Bezug, die nicht „Glied der heiligen, katholischen und apostolischen Kirche Gottes sind, in der die heiligsten Patriarchen der gesamten Ökumene, der des westlichen Rom, der dieser kaiserlichen Stadt (Konstantinopel), der von Alexandreia, der der Gottesstadt (Antiocheia), der von Jerusalem und alle ihnen untergeordneten heiligsten Bischöfe, sämtlich den Glauben und die Überlieferung der Apostel verkünden"89. Der Begriff der kirchlichen Ökumene ${ }^{90}$ - dies sei hier in Erinnerung gerufen - tritt in dem Maß stärker in den Vordergrund, in dem bei den Byzantinern das Bewußtsein von der Beschränktheit des politischen Anspruches auf Ökumenizität Platz greift; für Psellos, beispielsweise, ist Michael Kerullarios „der Patriarch der gesamten Ökumene - so ist es ja Gesetz, den (Kirchenfürsten) von Konstantinopel zu nennen“91.

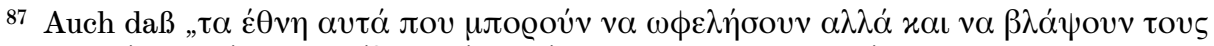

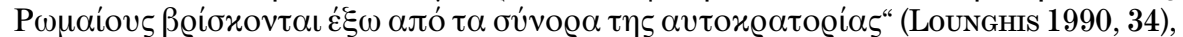
ist in vielen Fällen wahrscheinlich, aber nicht selbstverständlich.

${ }^{88}$ Freilich hatten schon seit langem die Perser eine Flexibilisierung des Oikumene-Begriffs bewirkt: Prokopios von Kaisareia spricht beispielsweise in De aed. 2.8.4-6 von den Grenzgebieten der Römer und der Perser, deren Ökumenen durch eine $\chi \omega \dot{\varrho} \alpha$...

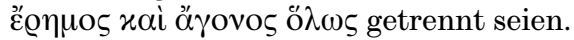

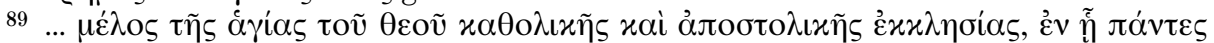

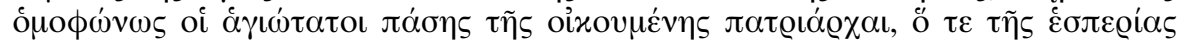

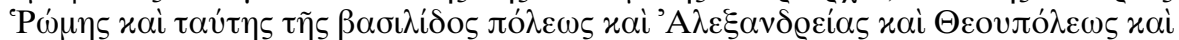

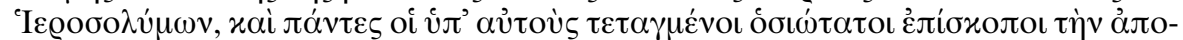

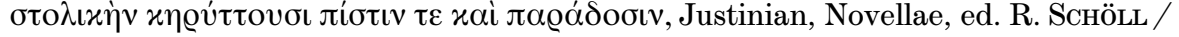
W. Kroll. Berlin 1895 (1968), 518 (Nov. 109), vgl. auch den Appell zur Einheit ebd.

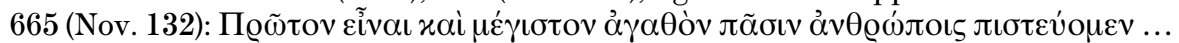

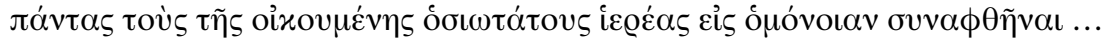

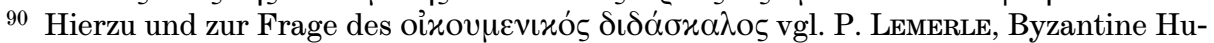
manism, The First Phase. Notes and Remarks on Education and Culture in Byzantium from its Origins to the 10th century, transl. by H. Lindsay / A. MofFatT. Canberra 1986, 93-98.

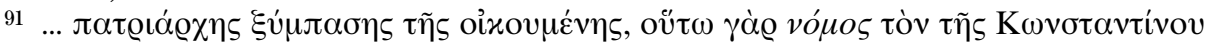

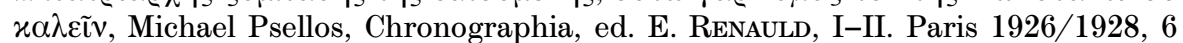
Theod. 17. - 1393 ist es dann der Patriarch von Konstantinopel (Antonios), der einen russischen Großfürsten (Vasilij Dimitriević) ermahnt, dem Kaiser trotz seiner evidenten politischen Schwäche den vollen Respekt zu erweisen, vgl. F. MıKLOSICH / J. MüLLER, Acta et diplomata graeca medii aevi, II, Wien 1862, 191f. (Nr. 447). 
Die stetige Entwicklung von der alles umfassenden Politik zur räumlich überschaubaren Außenpolitik wird nur für uns, durch den Wechsel in der Quellensituation seit dem 9. Jahrhundert, so „schlagartig“ wahrnehmbar. Die größere Zahl an schriftlichen Quellen bewirkt, daß wir spätestens ab der Zeit der makedonischen Dynastie (oder besser: spät- und nachikonoklastisch) „plötzlich“ mit einer (relativen) Informationsdichte und -fülle konfrontiert werden, die eine deutlichere Konkretisierung, Verpersönlichung und Regionalisierung der Geschichtsdarstellung ermöglicht als zuvor ${ }^{92}$.

Ab dem 11. Jahrhundert, besonders ab der seldschukischen Landnahme im Dezennium nach 1071, wird das politische Ökumeneverständnis der Byzantiner uneinheitlich, und die Divergenzen zwischen Realität und - zunehmend seltener artikuliertem - theoretischem Anspruch werden größer ${ }^{93}$. So steht Michael Psellos am Übergang von der einen zur andern Epoche, sowohl chronologisch als auch in seinem Verständnis von oikumene. Zum einen verbindet er das Wort bereits auffallend oft mit einschränkenden Formulierungen, die die politische Ökumenizität der Byzantiner relativieren: „die uns zugehörige Ökumene“, oder „unsere Ökumene“, beide unterschieden von „einer andern und wiederum andern und andern“ und insbesondere von der „den Barbaren zugehörigen Erde“94. Andererseits ruft Psellos den besonderen, von den Römern ererbten, historischen „Auftrag“ der Byzantiner (gegenüber den Barbaren) mit den folgenden Worten noch einmal in Erinnerung: „Seit damals ist von uns der Osten und der Westen befriedet und unterworfen worden - oder wann haben sich jemals die Teile der Ökumene mit der Unterwerfung einverstanden erklärt, und wann hat jemals der Barbaren Hand dem Frieden zugestimmt?" 95 .

\section{ANHANG: SPRACHLICHe ÖKUMENE}

Auf die sprachbezogenen Aussagemöglichkeiten zum byzantinischen Raumverständnis und die sprachlich gebundenen Kulturleistungen gehe ich nur kurz ein, um auf die wichtige sprachliche - und im weiteren Sinn auf die kulturelle Dimension des Begriffs oikumene hinzuweisen ${ }^{96}$. Angesichts der Tatsache, wie sehr sich - auch räumlich - die sprachlich-kulturelle von der politischen und

92 Grundlegend P. Lemerle 1986, passim, bes. $81 \mathrm{ff}$., $137 \mathrm{ff}$. und $347 \mathrm{ff}$ - - Gut erkennbar ist die Informationsverdichtung beispielsweise in der Hagiographie, die im 9. und 10. Jahrhundert regionale Heilige in vergleichsweise großer Zahl belegt, vgl. J. KARAyanNopulos / G. WeIss, Quellenkunde zur Geschichte von Byzanz (324-1453), II. Wiesbaden 1982, Nr. 222-239 (9. Jahrhundert), 283-294 (10. Jahrhundert); nur wenige im 11. Jahrhundert: KaraYANnOPOULOS / WeISs 1982, Nr. 360-362.

93 Vgl. J. Koder, „Zeitenwenden“. Zur Periodisierungsfrage aus byzantinischer Sicht, BZ 84/85 (1991/92) 409-422.

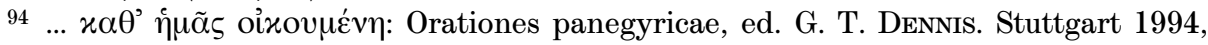

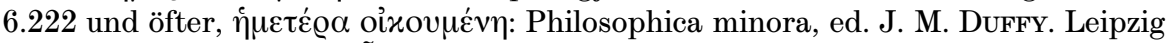

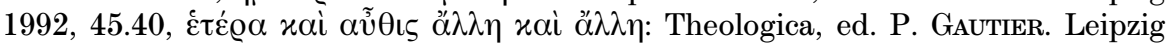

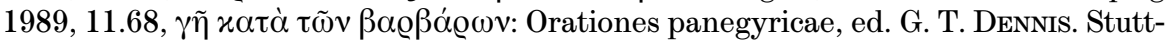
gart 1994, 10.21 .

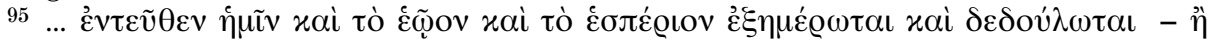

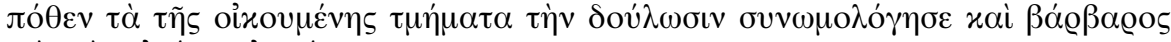

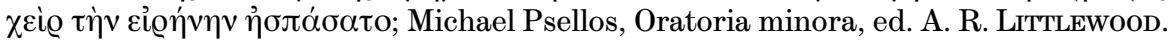
Leipzig 1985, $1.88 \mathrm{ff}$.

96 Beispielhaft sei vorweg Johannes von Damaskos genannt, der am Sitz des arabischen, muslimischen Kalifats der Omayyaden als griechischer, christlicher theologischer Schriftsteller wirkte. 
der ideologischen Entwicklung unterscheidet, bedürfte das Thema „sprachlich-kulturelle Ökumene" diesbezüglich einer eigenen Untersuchung.

Das Griechische erscheint im frühen Byzanz als geographischer Identifikationsfaktor noch keineswegs so dominant wie im Mittelalter, denn es steht zunächst neben dem zumindest gleichberechtigten Lateinischen und den Sprachen des Ostens, besonders dem Armenischen, dem Syrischen, dem Aramäischen ${ }^{97}$ und dem Koptischen ${ }^{98}$. Charakteristisch sind die (unterschiedlichen) Diglossien in bestimmten Reichsgebieten. Wir wissen beispielsweise, daß kirchliche Persönlichkeiten (wie Ephraim der Syrer, Johannes Chrysostomos, Theodoret von Kyrros oder Romanos Melodos) sowohl das Griechische als auch das Syrische beherrschten ${ }^{98 a}$. Direkt aus dem kirchlichen Alltag berichtet die Pilgerin Egeria über die Liturgie in Jerusalem (am Ende des 4. Jahrhunderts): Die Bevölkerung sei gemischtsprachig, der Bischof könne Griechisch und „Syrisch“, doch spreche er in der Kirche nur Griechisch, weshalb sich stets ein Priester neben ihm befinde, der in die „syrische“ Sprache übersetzt; aber auch für die Lateiner unter den Besuchern fänden sich stets graecolatini unter den anwesenden Brüdern und Schwestern, um für sie zu übersetzen ${ }^{99}$.

97 Gemeint ist hier das „Christlich-Aramäische“, vgl. S. H. GRIFFITH, From Aramaic to Arabic: The Languages of the Monasteries of Palestine in the Byzantine and Early Islamic Periods. DOP 51 (1997) 11-31; zur jüdischen Identität, besonders in Hinblick auf das sprachliche und kulturelle Selbstverständnis der Juden in Byzanz vgl. N. DE LANGE, Hebrews, Greeks or Romans? Jewish Culture and Identity in Byzantium, in: Strangers to Themselves: the Byzantine Outsider. Papers from the Thirty-second Spring Symposium of Byzantine Studies, University of Sussex, Brighton, March 1998, edited by Dion C. Smythe (Society for the Promotion of Byzantine Studies, Publications 8). Aldershot, Ashgate Variorum 2000, 105-118.

98 Literaturhinweise: H. Zilliacus, Zum Kampf der Weltsprachen im Oströmischen Reich. Helsingfors 1935 (ND 1965); H. MinaEscU, La lingua latina e la lingua greca nell' Impero Bizantino. Atene e Roma 18 (1973) 144-153; H. u. R. KAHANE, Graeca et Romanica, Scripta selecta, I. Romance and Mediterranean Lexicology, II. Byzantium and the West, III. Humanistic Linguistics. Amsterdam 1979/1981/1986; B. RochETTE, Justinien er la langue latine. A propos d'un prétendu oracle rendu à Romulus d'après Jean le Lydien. BZ 90 (1997) 413-415; Chr. GASTGEBER, Die lateinische „Übersetzungsabteilung" der byzantinischen Kaiserkanzlei unter den Komnenen und Angeloi (Diss. Universität). Wien 2001. - S. Rubenson, The Transition from Coptic to Arabic. Egypte / Monde arabe 27/28 (1996) 77-91; S. BRock, From Ephrem to Romanos. Interactions between Syriac and Greek in Late Antiquity (Variorum Collected Studies 664). Aldershot 1999; Th. UrbainczyK, "The devil spoke Syriac to me“. Theodoret in Syria, in: Mitchell, St. / Greatrex, G. (Hrsg.), Ethnicity and Culture in Late Antiquity. London 2000, 253-265. - Zum politischen Hintergrund vgl. etwa M. Wніттоw, The Making of Byzantium, 600-1025. Houndmills / London 1996, bes. $161 \mathrm{f}$.

${ }^{98 a}$ Noch im 6. Jahrhundert hatten Gesandte des Gotenkönigs Witigis, die nur des Gotischen und des Lateinischen mächtig waren, auf ihrer (geheimgehaltenen) Reise in das Perserreich die Möglichkeit, unterwegs in Thrakien einen Dolmetsch für die syrische

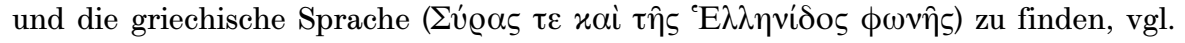
Prokop, Bella 2.2.1-3.

${ }_{99}$ Et quoniam in ea provincia pars populi et grece et siriste novit, pars etiam alia per se grece, aliqua etiam pars tantum siriste, itaque quoniam episcopus, licet siriste noverit, tamen semper grece loquitur et nunquam siriste. itaque ergo stat semper presbyter, qui episcopo grece dicente, siriste interpretatur, ut omnes audiant, quae exponuntur. Lectiones etiam quaecumque in ecclesia leguntur, quia necesse est grece legi, semper stat, qui siriste interpretatur propter populum, ut semper discant. Sane quicumque hic latini sunt, id est qui nec siriste nec grece noverunt, ne contristentur, et ipsis exponitur eis, quia sunt alii fratres grecolatini, qui latine exponunt eis, Egeria, Peregrinatio, c. 47.3-4, ed. N. NATALUCCI. Florenz 1990, 226-229. - Es muß offenbleiben, ob mit siriste vielleicht in Wirklichkeit Aramäisch gemeint ist. 
Die schrittweise Dominanz des Griechischen im Osten begann mit der Verwaltungsteilung des Imperium Romanum am Ende des 4. Jahrhun$\operatorname{derts}^{100}$. Schon die Kaiser Theodosios II. und Valentinian III. erließen einzelne Gesetze in griechischer Sprache ${ }^{101}$. Justinian rechtfertigte dann die Notwendigkeit, seine Gesetzesnovellen nicht nur in lateinischer, sondern auch in griechischer Sprache zu publizieren, mit der Begründung, auf Griechisch mache er sich der Masse verständlich, während das Lateinische die Herrschaftssprache des Römischen Reiches sei ${ }^{102}$.

Die Verengung des politischen Bezugsraumes bewirkt unter dem sprachlichen Aspekt durch den schrittweisen (fallweise auch nur befristeten) Verlust großflächiger Gebiete mit nicht Griechisch sprechenden Bevölkerungen, besonders im ausgehenden 6. und im 7. Jahrhundert, die Arabisierung der ehemaligen Diözesen Oriens und Aigyptos und die zunehmende Gräzisierung des verbleibenden byzantinischen Reichsgebietes, somit eine rasch deutlicher werdende Dominanz des Griechischen ${ }^{103}$. Dem enspricht eine „gräzisierende“ Binnenkolonisation (und Binnenmissionierung) im südosteuropäischen Reichsteil, die ebenfalls sprachlich und kulturell wirksam ist. Leon VI. bestätigt diese Politik für seinen Vater Basileios I. in Bezug auf einwandernde Slawen, die zur „Gräzisierung“, administrativen Unterordnung und Taufe gezwungen wurden ${ }^{104}$. In der Tradition seines Vaters und seines Großvaters stehend und in ausdrücklicher Distanzierung zu seinem Schwiegervater Romanos Lakapenos, betont Konstantin VII. im Zusammenhang mit Hinweisen darauf, was bei der Schließung politischer Ehen durch Angehörige der kaiserlichen Familie seiner Meinung nach zu beachten sei, die Bedeutung kollektiver (nationaler) Eigenheiten, wie Sitten ( $\left.\varepsilon^{\prime} \theta \eta\right)$, Gesetze (vó $\left.\mu \circ \iota\right)$ und traditionelle Normen ( $\theta \varepsilon \sigma \mu o i)$, besonders aber der gemeinsamen Sprache (,... so ist es

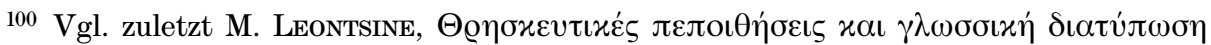

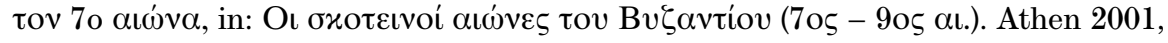
73-87.

101 Sp. Troianos, Römisches Recht und byzantinisches Recht. Juristische Kuriosa bei den „Exhellenismoi“, in: Byzantine Law. Proceedings of the Int. Symposium of Jurists 1998, ed. Ch. Papastathis. Thessaloniki 2001, 15-20, mit Verweis auf Codex Theodosianus 9.45.4 vom 23. März 431.

102 Justinian, Novelle 66.1.2, und Novelle 7.1 (Prooimion); vgl. H. Zilliacus 1935, wie Anm. 94, $70 \mathrm{ff}$.

103 Zur Teilhabe an der griechischen Sprache und Kultur als Identifikationsfaktor vgl. A. E. LaIOU, The Foreigner and the Stranger in 12th century Byzantium: Means of Propitiation and Acculturation, in: Fremde in der Gesellschaft. Historische und sozialwissenschaftliche Untersuchungen zur Differenzierung von Normalität und Fremdheit, hrsg. v. M. Th. FöGEN. Frankfurt / Main 1991, 71-97, hier (zusammenfassend) 76; vgl. weiters Matschke 1999, 18f., N. Oı́onomidès, L',unilinguisme“ officiel de Constantinople byzantine (VIIe-XIIe s.). Symmeikta 13 (1999) 9-22, und ders., Administrative Language and its Puplic Deployment, in: East and West: Modes of Communication, hrsg. v. E. Chrysos / I. Wood (The Transformation of the Roman World, 5). Leiden / Boston / Köln 1999, 47-59.

104 Leon VI. Taktika, Diataxis 18, 101 (PG 107, Sp. 969). - Vgl. hierzu auch die Feststel-

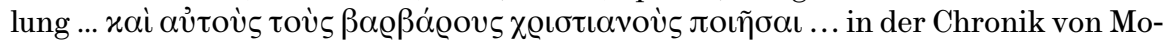

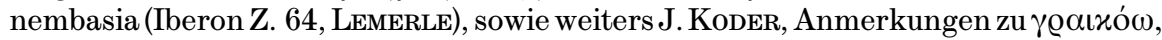
in: Gedenkschrift I. E. Karagiannopoulos, Byzantina 21 (2000) 199-202. - Wenn dann diese (auch zwangsweise) Akkulturierung nach dem Geschmack der Byzantiner zu erfolgreich war, konnte dies zu kritischen Abwehrreaktionen führen, wie sie sich in dem von Konstantinos Porphyrogennetos (De thematibus 6.40, 91 PERTUSI) zitierten

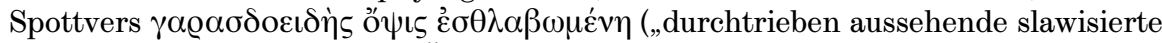

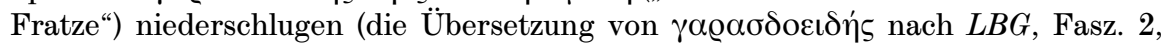
1996, 309a, s. v.). 
auch recht, daß jedes Volk seine Ehegemeinschaften nicht mit Menschen eines anderen Stammes und mit anderer Sprache schließt, sondern mit Stammesgenossen, die auch die selbe Sprache sprechen" ${ }^{105}$.

Mit dieser Ansicht mag Konstantin zu seiner Zeit noch allein sein, doch kann dann das späte Byzanz, besonders der „nizänische“ Staat zwischen 1204 und 1261, sehr wohl die Sprache und deren Kulturtradition als einen nationalen Identifikationsfaktor einsetzen, indem man etwa „uns Griechen“ (

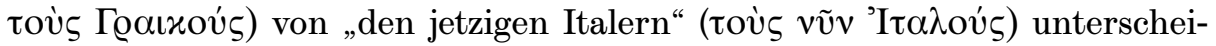
$\operatorname{det}^{106}$.

Dieses Byzanz des Hoch- und Spätmittelalters ist kultursprachlich im wesentlichen tatsächlich eine griechische Ökumene.

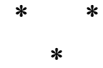

Im vorangehenden Überblick wurde versucht, wesentliche Aspekte der räumlichen Dimension der Ökumene-Vorstellungen in ihrer Entwicklung und ihrem Wechselspiel zwischen frühem Christentum, kaiserzeitlichem Rom und Byzanz, zwischen Ideologie, Eschatologie und Politik zu skizzieren. Hierbei ging es vor allem um jene Phänomene (und die dahinter stehenden gesellschaftlichen Schichten), die in der historiographischen und der theologischen Literatur der Byzantiner artikuliert werden. Auf die Ökumene des Alltags bin ich nur am Beginn der Darstellung ausdrücklich eingegangen. Dies erklärt sich zum einen mit der Einfachheit und der kulturübergreifenden Einheitlichkeit des den Menschen jeder vorindustriellen Kultur spontan erlebbaren bzw. bewußten und immanenten, ursprünglichen räumlichen Ökumenebegriffs, und zum andern damit, daß konkret in Byzanz die Vorstellungen und Leitbilder der ideologisch, kulturell und politisch prägenden Schichten auf die große Masse der Bevölkerung jedenfalls stets dann einwirkten, wenn sich deren subjektive Ökumene-Vorstellungen über die unmittelbar erlebbare Ökumene des persönlichen Lebensraumes hinaus erweiterten. Diese prägenden gesellschaftlichen Schichten artikulierten sich aber in den oben behandelten literarischen Quellen.

Vorgelegt vom Verfasser

in der Sitzung am 4. Oktober 2002.

105 DAI, c. 13.175-181, die Übersetzung nach K. BeLKE / P. Soustal 1995, wie A. 82, 98. - Hinzuweisen ist hier auch Liutprand von Cremonas Unterscheidung zwischen der gens Graecorum (als übergeordnetem Begriff) und den nationes Grecae (in der Antapodosis 1.7 und 6.2).

106 So der Patriarch Germanos in seinem 2. Brief an die Kyprier (1223), ed. K. N. Sathas,

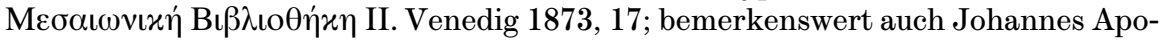
kaukos, Metropolit von Naupaktos († 1233), mit der in einem Brief an den Kaiser ge-

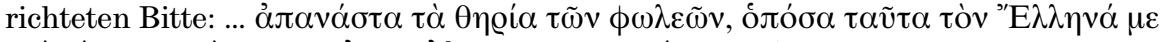

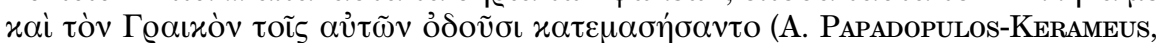
Noctes Petropolitanae. St. Peterburg 1913, hrsg. v. K. Treu. Leipzig 1976, 273). - Vgl. weiters J. Koder, Plenary Session I: The Identity of Byzantium, Byzantinische Identität - einleitende Bemerkungen, in: Byzantium. Identity, Image, Influence. XIX. Int. Congress of Byz. Studies, Major Papers, hrsg. v. K. Fledelius. Kopenhagen 1996, 3-6. 